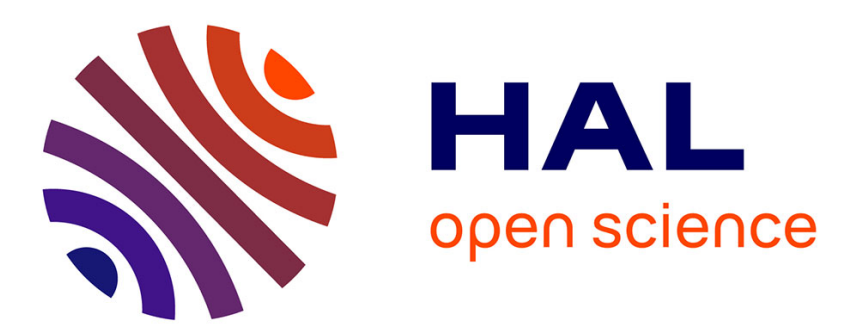

\title{
Sizing of a stand-alone microgrid considering electric power, cooling/heating, hydrogen loads and hydrogen storage degradation
}

Bei Li, Robin Roche, Damien Paire, Abdellatif Miraoui

\section{- To cite this version:}

Bei Li, Robin Roche, Damien Paire, Abdellatif Miraoui. Sizing of a stand-alone microgrid considering electric power, cooling/heating, hydrogen loads and hydrogen storage degradation. Applied Energy, 2017, 205, pp.1244 - 1259. hal-02131008

\section{HAL Id: hal-02131008 \\ https://hal.science/hal-02131008}

Submitted on 16 May 2019

HAL is a multi-disciplinary open access archive for the deposit and dissemination of scientific research documents, whether they are published or not. The documents may come from teaching and research institutions in France or abroad, or from public or private research centers.
L'archive ouverte pluridisciplinaire HAL, est destinée au dépôt et à la diffusion de documents scientifiques de niveau recherche, publiés ou non, émanant des établissements d'enseignement et de recherche français ou étrangers, des laboratoires publics ou privés. 


\title{
Sizing of a stand-alone microgrid considering electric power, cooling/heating, hydrogen loads and hydrogen storage degradation
}

\author{
Bei $\mathrm{Li}^{\mathrm{a}, \mathrm{c}, *}$, Robin Roche ${ }^{\mathrm{a}, \mathrm{c}}$, Damien Paire ${ }^{\mathrm{a}, \mathrm{c}}$, Abdellatif Miraoui ${ }^{\mathrm{b}, \mathrm{c}}$ \\ ${ }^{a}$ FEMTO-ST, CNRS, Univ. Bourgogne Franche-Comte, UTBM, rue Thierry Mieg, F-90010 Belfort Cedex, France \\ ${ }^{b}$ Univ. Bourgogne Franche-Comte, UTBM, rue Thierry Mieg, F-90010 Belfort Cedex, France \\ ${ }^{c}$ FCLAB, CNRS, Univ. Bourgogne Franche-Comte, rue Thierry Mieg, F-90010 Belfort Cedex, France
}

\begin{abstract}
Microgrids are small-scale power systems with local generation, storage systems and load demands, that can operate connected to the main grid or islanded. In such systems, optimal components sizing is necessary to make the system secure and reliable, while minimizing costs. In this paper, a stand-alone microgrid considering electric power, cooling/heating and hydrogen consumption is built. A unit commitment algorithm, formulated as a mixed integer linear programming problem, is used to determine the best operation strategy for the system. A genetic algorithm is used to search for the best size of each component. The influence of three factors (operation strategy, accuracy of load and renewable generation forecasts, and degradation of fuel cell, electrolyzer and battery) on sizing results is discussed. A 1-hour rolling horizon simulation is used to check the validity of the sizing results. A robust optimization method is also used to handle the uncertainties and evaluate their impact on results.
\end{abstract}

Keywords: multi-energy, microgrid, sizing, unit commitment, evolutionary algorithm, degradation.

\section{Nomenclature}

\section{Acronyms}

CCHP combined cooling heat and power

CHP combined heat and power

DG distributed generation

EA evolutionary algorithm

FC fuel cell

FCL following the cooling load

FEL following the electric load

FTL following the thermal load

GA genetic algorithm

MG microgrid

MILP mixed integer linear problem

MINLP mixed integer nonlinear problem

MIP mixed integer problem

MRM maximum rectangle method

\footnotetext{
${ }^{*}$ Corresponding author.

Email addresses: bei.li@utbm.fr (Bei Li), robin.roche@utbm.fr (Robin Roche), damien.paire@utbm.fr (Damien Paire), abdellatif.miraoui@utbm.fr (Abdellatif Miraoui)
}

PSO particle swarm optimization

UC unit commitment

\section{Symbols}

$\Delta V_{e l} \quad$ voltage increase of electrolyzer

$\Delta V_{f c} \quad$ voltage drop of FC

$\dot{n}_{H 2}^{c o n} \quad$ FC consumed hydrogen

$\dot{n}_{H 2}^{\text {pro }} \quad$ production rate of hydrogen in electrolyzer

$A C_{\text {cost }}(t)$ utilization cost of air conditioner in time $t$

$A H C_{\text {cost }}(t)$ utilization cost of absoption heat chiller in time $t$

$B_{\text {cost }}^{\text {ch,dis }}(t)$ utilization cost of battery storage system in time $t$

$C^{i n v} \quad$ investment cost

$C^{m n t} \quad$ annual maintenance cost

$C_{a c} \quad$ produced cooling by air conditioner

$C_{a h c} \quad$ produced cooling by absorption heat chiller

$C_{o p} \quad$ total operation cost

$F($.$) \quad total cost function$

$H_{\text {cost }}^{\text {ele }}(t)$ utilization cost of electrolyzer in time $t$

$H_{\text {cost }}^{f c}(t)$ utilization cost of fuel cell in time $t$

$H B_{\text {cost }}(t)$ utilization cost of heat boiler in time $t$ 
$H S(t)$ state of the heat storage system in time $t$

$H S_{\text {cost }}(t)$ utilization cost of heat storage system in time $t$

$I_{e l} / A_{e l}$ current density of the electrolyzer

$i_{f c} \quad$ FC current density

$k_{e l} \quad$ electrolyzer produced hydrogen coefficient

$k_{e l}\left(t_{d a y}\right)$ hydrogen produced coefficient value in time $t_{d a y}$

$k_{f c} \quad$ FC consumed hydrogen coefficient

$k_{f c}\left(t_{d a y}\right)$ FC consumed hydrogen coefficient in time $t_{d a y}$

$k_{\text {run }} \quad$ continue run time steps of fuel cell and electrolyzer

$L_{\text {cooling }}(t)$ cooling load demand in time $t$

$L_{H_{2}}(t)$ hydrogen load demand in time $t$

$L_{\text {heat }}(t)$ heating load demand in time $t$

$L_{\text {power }}(t)$ electric load demand in time $t$

$L O H(t)$ level of hydrogen in time $t$

$P_{a c} \quad$ input power of air conditioner

$P_{c h}(t) \quad$ charging power of battery

$P_{\text {dis }}(t)$ discharging power of battery

$P_{\text {ele }}^{\max }\left(t_{\text {day }}\right)$ maximum input power of electrolyzer in time $t_{\text {day }}$

$P_{e l} \quad$ input power of electrolyzer

$P_{f c} \quad$ FC output power

$P_{f c}^{\max }\left(t_{d a y}\right)$ FC maximum output power in time $t_{d a y}$

$P_{h b} \quad$ input power of heat boiler

$P V(t)$ output power of PV in time $t$

$Q_{a h c} \quad$ input heat of absorption heat chiller

$Q_{f c} \quad$ FC produced heat

$Q_{h b} \quad$ produced heat by heat boiler

$Q_{s h}(t)$ solar heating of PV in time $t$

$S O C(t)$ state-of-charge in time $t$

$t_{\text {day }} \quad$ operation time of FC

$V_{e l} \quad$ voltage of the electrolyzer

$V_{f c} \quad$ FC voltage

\section{Variables}

$\Delta \delta_{i}(t) \quad$ whether component $i$ started or not in time $t$

$\delta_{\text {ele }}(t) \quad \mathrm{ON} / \mathrm{OFF}$ state of electrolyzer in time $t$

$\delta_{f c}(t) \quad \mathrm{ON} / \mathrm{OFF}$ state of fuel cell in time $t$ $\delta_{j}(t) \quad \mathrm{ON} / \mathrm{OFF}$ state of component $j$ in time $t$

$\gamma_{1}^{j} \quad$ minimum power of component $j$

$\gamma_{2}^{j} \quad$ maximum power of component $j$

$C B \quad$ capacity of battery

$\operatorname{cut}_{P V}(t)$ curtailed power of PV in time $t$

$\operatorname{cut}_{\text {solar }}(t)$ curtailed solar heating of PV in time $t$

$H S_{\max }$ maximum volume of heat storage system

$L S_{\text {cooling }}(t)$ coolting load shedding in time $t$

$L S_{\text {heat }}(t)$ heating load shedding in time $t$

$L S_{\text {power }}(t)$ electric load shedding in time $t$

$N_{P V} \quad$ number of PV panels

$N_{s h} \quad$ number of solar panels

$P_{a c}^{\max } \quad$ maximum power of air conditioner

$P_{e l}^{\max }$ maximum input power of electrolyzer

$P_{f c}^{\max } \quad$ FC maximum output power

$P_{h b}^{\max } \quad$ maximum power of heat boiler

$P_{j}(t) \quad$ power of component $j$ in time $t$

$Q_{a h c}^{\max } \quad$ maximum power of absorption heat chiller

$Q_{h s c h}(t)$ heat storage input power in time $t$

$Q_{h s d i s}(t)$ heat storage output power in time $t$

$V_{H_{2}}^{\max } \quad$ maximum volume of hydrogen tanks

$Z_{a c}(t)$ actual input power of air conditioner in time $t$

$Z_{\text {bach }}(t)$ actual input power of battery in time $t$

$Z_{\text {badis }}(t)$ actual output power of battery in time $t$

$Z_{\text {ele }}(t)$ actual input power of electrolyzer in time $t$

$Z_{f c}(t)$ actual output power of fuel cell in time $t$

$Z_{h b}(t)$ actual input power of heat boiler in time $t$ 


\section{Introduction}

Power systems are increasingly suffering from damage caused by natural disasters (e.g., hurricanes, storms, floods, earthquakes), which often result in blackouts and power interruptions [1]. In traditional centralized power supply systems, no alternative power source can be used if the main distribution network is damaged by a natural disaster, which makes traditional power systems fragile. Through distributed generation (DG), loads can be powered by local resources, which reduces the dependence on the rest of the system and improves overall power system resilience. Local DGs and loads can be combined to build a microgrid (MG), which has multiple benefits such as the ability enhance resistance to natural disasters [1, 2]. For local DGs, a conventional source is diesel gensets, which have some drawbacks such as the emissions resulting from their operation, as well as dependence on fuel supply $[1,2]$. Generation from renewable energy sources can also be considered to form a renewable energy-based $\mathrm{MG}$.

In this work, we consider microgrids with multiple energies, including electric, thermal and hydrogen loads (Fig. 1). Combined heat and power (CHP) plants are typically efficient and economical, and have applications in the residential and industrial sectors, especially when multiple energies are considered $[3,4,5]$. Similarly, fuel cells are a promising technology for efficient and sustainable energy conversion [6], and are expected to play an important role in future distributed energy generation [7]. Fuel cells are thus considered for a CHP plant. A fuel cell can operate as the main MG power plant to serve the electric and heat load demand of the whole system. Electric loads are powered by PV panels, a fuel cell, and a battery system; heating loads are heated by a solar heating system, a heat boiler, heat from the fuel cell, and a heat storage system; cooling loads are cooled by an air conditioner and an absorption heat chiller. In order to balance the intermittent and varying PV output, an electrolyzer and a battery are used. The electrolyzer is used as a long-term storage unit, which can convert electrical power to hydrogen stored in hydrogen tanks. The fuel cell, the electrolyzer and the hydrogen tanks operate as a long-term storage system, which has several advantages, such as a high storage capacity, and a high energy per unit of volume [8]. The battery system is used as a short-term storage and is inappropriate for long-term storage, due to its low energy density and nonnegligible self-discharge rate [9]. Similarly, heat storage is used to balance heat power (heat from the fuel cell, and intermittent heat from the solar heating system).

A multiple-energy system is a key aspect to evolve toward a cleaner and affordable energy supply system [10] and to improve power system resilience [11]. But how to decide the capacity of each component in this complex system with a given load profile remains a challenge. For example, if the components are oversized, capital and operation costs will be higher, while if the components are undersized, generation curtailment or load shedding may occur. This means that the sizing results are affected not only by the architecture of system, but also by the operation strategy [12]. Depending on how components are used, the necessary capacity may vary greatly, which in turn

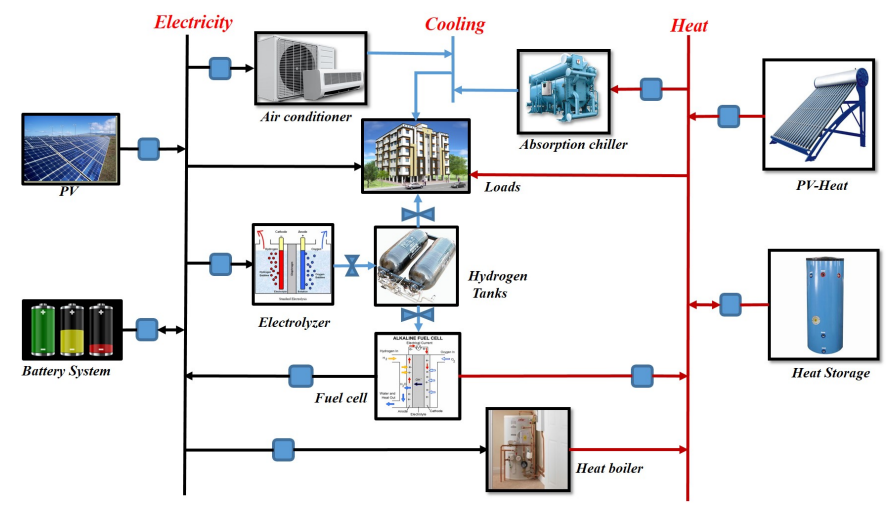

Figure 1: Stand-alone microgrid architecture.

impacts sizing results. On the other hand, input data (load demand, PV output) forecasting errors also influence how components are used. This means that forecasting errors must be considered. At last, due to the fact that the fuel cell and the electrolyzer are used as the main storage system, and as operation time goes, the performance of fuel cell and electrolyzer can be expected to decrease, so this degradation process must also be considered [13, 14].

In this paper, we decompose the sizing problem into a leaderfollower problem. The follower problem, namely, the energy management strategy, is formulated as a unit commitment problem, in the form of mixed integer problem. We use linear programming (LP) to obtain the optimal operation strategy. The leader problem, namely, the sizing problem, uses an evolutionary algorithm (EA) to search for the best sizing values [15]. In our previous paper [16], we use this method to research about the sizing problem of an islanded MG (where only electric energy was considered), and simulation results showed the interest of this co-optimization method. In this paper, a combined cooling/heat/power and hydrogen microgrid is considered, while we also consider the influence of fuel cell and electrolyzer degradation on sizing results.

The main contributions of this paper include:

1. The design of a combined cooling/heat/power and hydrogen microgrid system based on a hybrid storage system.

2. The development of a degradation model of the fuel cell and the electrolyzer to evaluate how time and use influence efficiency. The influence of this degradation on sizing results is then investigated.

3. To reduce the degradation of the hydrogen storage system, startup and shutdown times and up and down times are considered. Three operation strategies are compared to analyze their influence on sizing results.

4. A 1-hour resolution rolling-horizon simulation is used to verify the validity of the sizing results for the whole system. A robust method is then used to assess the impact of the forecasting errors on load demand and PV output.

The remainder of this paper is organized as follows. Section 2 discusses related work. Section 3 describes the system model, Section 4 the operation strategy, Section 5 the sizing 
methodology, and Section 6 the simulation results. Finally, Section 7 concludes the paper.

\section{Related work}

In this section, we review related work about the optimal sizing problem of MG. The sizing of MG is influenced by two main factors: the operation strategy, which determines the power flow in the whole system, and the forecasting error on input data (load demand, PV output, etc.).

\subsection{Operation strategy}

The operation strategy of a combined cooling heat and power (CCHP) system needs to be considered from two aspects: time scale and solution method. Based on the selected time scale, two strategies can be considered: day-ahead scheduling and short term dispatching. A day-ahead scheduler provides unit commitment solutions aiming to find cost-effective combinations of generating units output, while a short term dispatcher returns the economic dispatch aiming to minimize the operation cost of the committed assets based on short term forecasts. In [17], authors review the energy management of a microgrid, and point out that based on the time scale, two scheduling strategies (unit commitment and economic dispatch) are used together. In [18], a multi-timescale MG scheduling and dispatching strategy is developed for the coupled multi-type energy supply in an MG. In day-ahead scheduling, the objective function is to minimize the operation cost, and the objective of real-time dispatching is to make the real-time actual electricity power exchange between the MG and to make the main grid follow its day-ahead schedules as close as possible. In [19], authors present a two-stage coordinated control approach for CCHP microgrid energy management. The first stage is a rolling-horizon economic dispatch. The second stage is a realtime adjustment stage, which adjusts the controllable sources to make the real-time energy exchanged with the main grid and the state of the battery follow its economic dispatch as closely as possible. In our sizing problem, the time duration is equal to one year, considering the tradeoff between accuracy and the computation burden. Hourly profiles are adopted in the operation strategy [20].

Regarding the solution method (i.e., decision-making), the operation strategies of a CCHP system can be divided into two main types: rule-based operation strategies and optimizationbased operation strategies.

In the studied multi-energy system, several loads must be satisfied. This means that some priority rules must be set, leading to traditional rule-based strategies: following the electric load (FEL), following the thermal load (FTL) or following the cooling load (FCL). In [21], authors review different optimization operation strategies, including basic operation strategies and hybrid operation strategies. [22] presents a novel optimal operational strategy for a CCHP system based on two typical operating modes: FEL and FTL. An integrated performance criterion which considers primary energy consumption, carbon dioxide emissions and operational cost, is used to decide which operating mode is chosen. In [23], authors compare five strategies: electrical-equivalent load following, continuous operation, peak shaving, and base load. In [24], four operation strategies are compared: FCL, FTL, FEL, maximum power output, and waste heat allocation proportion. [25] presents a multi-agent-based demand-side energy management system for autonomous polygeneration microgrids. with three types of demands (electricity, hydrogen, potable water). The goals are to have no potable water and hydrogen shortage, and to prevent the battery from deep discharging. The activation of each agent is based on rules. These rule-based operation strategies are however difficult to use for complex systems, where a large number of rules are needed, especially in multiple energy system.

Due to the drawbacks of rule-based strategies, optimization methods are also commonly used. A first category includes heuristic optimization methods, which are adequate to solve non-linear and non-convex problems. [26] proposes a time-varying acceleration coefficient particle swarm optimization (PSO) algorithm to solve the non-linear and non-convex CHP economic dispatch problem. The objective is to minimize the total heat and power production cost. [27] presents an artificial immune system algorithm for solving the CHP economic dispatch problem. The objective is to minimize the total fuel cost. [28] proposes a bacterial foraging-based fuzzy satisfactory optimization algorithm to solve the multi-objective energy management problem for a CHP-based microgrid. The objectives are to minimize the total operating cost and the emissions. [29] introduces a multi-objective PSO economic dispatch optimization method for a system that incorporates CHP and wind power units. [30] proposes a multi-objective optimization model which aims to maximize the energy-saving ratio and minimize the energy costs of a micro-CCHP system. [31] presents a scenario-based scheduling method for a fuel cell-based CHP microgrid, which aims at maximizing the expected profit. A modified firefly algorithm is used to solve the problem.

EA-based optimization relies on stochastic search, which can give a satisfatory solution with a reasonable computation time, but it does not guarantee obtaining an optimal solution.

The second category corresponds to mixed integer programming optimization (MIP), which uses deterministic methods. [32] explores opportunities for increasing the flexibility of CHP units using electrical boilers and heat storage tanks for better integration of wind power. A linear model is proposed for the centralized dispatch of integrated energy systems. [33] presents a mixed integer linear problem (MILP) optimization model for combined cooling, heat and power system operation. The objective is to minimize the total operation and maintenance costs. [34] presents the optimization of a CCHP system using MILP to determine the preliminary design of such systems with thermal storage. The objective function is to minimize the total annual cost. The effect of legal constraints in the design and operation of CCHP systems is highlighted in this study. In [35], the objective of the operation strategy is to maximize the gross operational margin and net present value, and the problem is formulated as an MIP model. In [36], the optimal control problem is formulated as a mixed integer nonlinear program (MINLP), 
and is solved using discrete dynamic programming. In [37], an MILP algorithm is used to solve the optimal dispatch problem, and the objective function is to minimize the operation cost. In [38], an operation strategy is formed as an MILP problem aiming to maximize greenhouse gas emissions reductions.

Unit commitment (UC) optimization, formed as an MIP problem, can be solved using a linear-programming based branch-and-bound algorithm [39], which is appropriate to solve energy management problems in CCHP systems. The optimal sheduling set points are determined based on current and future conditions, which can guarantee obtaining the global optimal results.

In our CCHP system, a rule-based operation strategy is difficult to use, because a large number of rules would need to be built to satisfy the power flow and system constraints. In EA operation strategies, premature convergence and reasonable computation times need to be considered. In this paper, we adopt the UC optimization method to control the operation of the microgrid system. The optimization problem is formed as an MILP problem, and several constraints are used to describe different operation strategies.

\subsection{Uncertainty}

Due to the fact that forecasting errors on load demand and PV output are unavoidable, and the accuracy of input data influences the actual power flow in the system, our scheduling algorithm must consider these errors. Two main methods can be used to handle such uncertainty: scenario-based methods [40, 41, 42] and robust optimization [43, 44, 45, 46]. [40] presents a stochastic method based on cloud theory to reflect uncertainties, and uses a krill herd method (a metaheuristic optimization algorithm that copies the search performance of krills during the foraging process) to solve the optimization problem. [41] presents an energy and reserve scheduling method for an MG based on stochastic optimization. Five interval wind speed and solar irradiance discrete probability distribution functions are considered for wind and PV generation fluctuation for each hour. Then a scenario tree technique is used to combine different states of wind and PV fluctuations. [42] presents a scenariobased robust energy management method to account for the worst-case amount of renewable generation and load. Taguchis orthogonal array testing method is used to provide possible testing scenarios, and then the worst-case scenario is found. The Monte Carlo method is used to verify the robustness of the energy management method. In [43], the uncertain operational and environmental parameters of the microgrid are quantified in terms of prediction intervals by a non-dominated sorting genetic algorithm (NSGA-II)-trained neural network, which gives the lower and upper prediction bounds between which the uncertain value is expected to lie with a given confidence. Then robust optimization is used to achieve optimal scheduling under uncertainty. [44] presents a robust optimization-based scheduling method for multi-microgrids considering uncertainty. The problem is transformed into a min-max robust counterpart, and solved using linear duality theory and Karush-Kuhn-Tucker optimality conditions. [45] proposes a robust UC model to minimize the generalized social cost which considers the uncertainty of the price elasticity of demand. This is a min-max problem which is converted into an MILP problem by dualizing the inner maximization problem. [46] presents a robust EMS for MGs. Authors use a fuzzy prediction interval model to obtain the uncertainty boundaries of wind output. The upper and lower boundaries of wind energy are then interpreted as the best and worst-case operating conditions.

From the above papers, we can see that scenario-based methods usually require generating many scenarios, which can take a lot of simulation time. On the other hand, robust methods are used to find the worst case, which requires less computation time, although results are more conservative. As a consequence, in this paper, in order to consider the influence of different forecasting errors levels and reduce the computation time, a robust optimization method is selected to find the worst case and best case based on the forecasting error.

\subsection{Sizing method}

The traditional sizing method for CCHP systems is the maximum rectangle method (MRM) which uses the hourly load curve and finds the rectangle area under this curve [47], [48]. EA are also used to search for the optimal sizing of MGs. $[49,15]$ compare different heuristic techniques to find the optimal sizing of $\mathrm{MG}$, where the objective function is the total annual cost. ACO [50], ABSO [51], SA [52], and PSO [53] methods are also used to compute the optimal size of MG.

Co-optimization methods have also been used to search for the optimal sizing values. There are different types of cooptimization methods. The first type uses sizing values chosen from a set of discrete values, and the operation strategy is based on rules. For example, [23] presents a method to design a trigeneration plant. Operation strategies are based on rules. The objective of this trigeneration planning model is to minimize the energy production and investment costs over the planning horizon, achieving maximum investment returns. The sizing value of each component is selected from a set of discrete values. [24] researches about the operation and configuration optimization of a CCHP system. Firstly, it chooses different configurations of sizing values, then chooses an operation strategy (FCL, FTL, FEL, and maximum power output) and waste heat allocation proportion. At last, the daily costs are compared, and the optimal system configuration is obtained.

The second type of co-optimization method has sizing values chosen from a set of discrete values, and the operation strategy is based on an optimization method. For example, [54] presents an optimal sizing method for cogeneration systems in two steps: first the capacity of each equipment is selected from a set of discrete values, then the optimal operation problem is solved using MINLP based on the above sizing values. [55] presents a generic deterministic linear programming model (which aims to minimize expected annual cost of the system) to determine the optimal size of a micro-CHP unit. [35] presents an optimal design method for a hospital complex. The objective of the operation strategy is to maximize the gross operational margin and net present value. It is formulated as an MIP model.

The third type of methods uses sizing values chosen using an evolutionary algorithm, and the operation strategy is based 
on rules. For example, in [56], authors adopt MRM to determine the lower and higher limits for the total nominal power of the prime mover. GA is used to search for the optimal sizing value of each component. Four operation strategies based on rules are compared. The objective function is named relative annual benefit, and includes investment and maintenance costs of equipment, buying and selling electricity, as well as operational and environmental costs. [57] presents an optimizationbased sizing method for CCHP. GA is used to search for the best sizing values, and the objective function is to minimize the total fossil energy consumption. Two operation strategies (improved strategy and base FEL strategy) are compared, and the primary energy saving ratio is employed to evaluate the strategy. [58] describes a thermodynamic performance analysis to optimize the configurations of a hybrid CCHP system incorporating solar energy and natural gas. GA is used to search for the best configuration, and the operation strategy is based on rules. The objective function is to maximize the annual primary energy savings and the annual total cost savings.

The fourth type of methods relies on sizing values chosen using an evolutionary algorithm, and an operation strategy based on optimization. For example, [36] presents a multi-objective model based optimization approach for the optimal sizing of all components. GA and non-linear mesh adaptive direct search method are used to decide the sizing values. The objectives are the capital expenditure, the levelized cost of energy, and emissions. The optimal control problem is formulated as an MINLP, and is solved using discrete dynamic programming. In [59], authors present a bilevel program for islanded MG with compressed air energy storage. The upper level problem is solved using GA, and the lower level problem is solved using the MILP technique. [37] presents a two-stage optimal planning and design method for a CCHP microgrid system. On the first stage, a multi-objective GA based on NSGA-II is applied to solve the optimal design problem. The objective function is to minimize the total net present cost and carbon dioxide emissions. On the second stage, an MILP algorithm is used to solve the optimal dispatch problem, where the objective function is to minimize the operation cost.

In addition to the above main types, a few other cooptimization methods can be mentioned. For example, in [38], the authors provide an analysis that shows that CHP systems should be sized and operated to reduce greenhouse gas emissions. A controlled random search method is used to search for optimal sizing values, and the operation strategy is formulated as an MILP problem aiming to maximize greenhouse gas emissions reductions. In [60], authors present a co-optimization method for microgrid planning in electrical power systems. The leader problem optimizes the planning decisions for the MG and the main grid. Then, with the proposed plan, the shortterm and economic operation subproblems are solved to check constraints violations. In [61], authors present an MG planning model. This problem is decomposed into an investment master problem and an operation subproblem. The two problems are linked via the benders decomposition method. In [62], a multiobjective MINLP model is formulated for the simultaneous system synthesis, technology selection, unit sizing, and operation optimization of a large-scale CCHP system. The objective function is to minimize the total annual cost and the annual global $\mathrm{CO}_{2}$ emissions. The augmented constraint method is applied to determine the Pareto frontier of the design configuration.

The reviewed co-optimization methods are summarized in Table 1.

Table 1: Selected papers on co-optimization methods.

\begin{tabular}{|l|c|c|}
\hline Refs. & Sizing method & Operation strategy \\
\hline$[54]$ & discrete values & MINLP \\
{$[55]$} & discrete values & LP \\
{$[23,24]$} & discrete values & rule-based \\
{$[56,57,58]$} & GA & rule-based \\
{$[35]$} & discrete values & MIP \\
{$[36]$} & GA/NOMAD & MINLP \\
{$[59]$} & GA & MILP \\
{$[62]$} & augmented $\varepsilon$-constraint & MINLP \\
{$[37]$} & NSGA-II & MILP \\
{$[38]$} & controlled random search & MILP \\
\hline
\end{tabular}

From the above review, we can conclude that the sizing problem is a hybrid optimization problem. Based on a given operation strategy, different sizing combinations are generated to run the strategy. However, no related paper has researched the sizing problem of islanded microgrids while considering the degradation of hydrogen storage, especially when considering multiple energies. In this paper, we therefore research about the optimal sizing problem using the co-optimization method. Namely, GA is used to search for the sizing values, and UC optimization is used to derive the operation strategy.

\section{Components models}

In this paper, the stand-alone microgrid is assumed to contain nine components: PV panels, a solar heating system, a battery storage system, a hydrogen storage system (including an electrolyzer, hydrogen tanks and a fuel cell), a heat boiler (which uses electricity to produce heat), an air conditioner, an absorption heat chiller (which uses heat to produce cooling), a heat storage system, and electric, thermal, cooling and hydrogen loads.

\subsection{Solar generation components}

The output of the PV generator can be calculated from [59, 63]:

$$
P_{P V}=N_{P V} \cdot f_{P V} \cdot P_{S T C} \cdot \frac{G_{A}}{G_{S T C}} \cdot\left(1+\left(T_{C}-T_{S T C}\right) \cdot C_{T}\right)
$$

where $N_{P V}$ is the number of $\mathrm{PV}$ panels, $f_{P V}$ the conversion efficiency, $P_{S T C}$ the PV array power under standard test conditions (STC), $G_{A}$ the global solar radiation on the PV array, $G_{S T C}$ the solar radiation under STC, $T_{C}$ the temperature of the PV cells, $T_{S T C}$ the STC temperature $(298 \mathrm{~K})$, and $C_{T}$ the PV temperature coefficient. 
For the solar heating system, the output is computed with [64]:

$$
Q_{s h}=N_{s h} \cdot \eta_{s h} \cdot G_{A}
$$

where $N_{s h}$ is the area of the heating system, and $\eta_{s h}$ its efficiency.

\subsection{Fuel cell model}

A fuel cell (FC) can produce electricity from hydrogen $\left(H_{2}\right)$, which can be drawn from hydrogen tanks. In this paper, we use the voltage electrical model presented in [65] to describe the characteristic of FC:

$$
V_{f c}=\left(E_{O C}-r_{f c} \cdot i_{f c}-a \cdot \ln \left(i_{f c}\right)-m \cdot e^{n_{0} \cdot i_{f c}}\right) \cdot N_{f c}
$$

where $V_{f c}$ is the FC voltage, $E_{O C}$ is the open-circuit voltage of one cell, $i_{f c}$ is the current density in one cell, $N_{f c}$ is the number of cells, and $n_{0}, r_{f c}, a$, and $m$ are empirical coefficients.

As an FC generates electricity and heat at the same time, the produced heat can be calculated as in [66]:

$$
Q_{f c}=N_{f c} \cdot\left(1.48-\frac{V_{f c}}{N_{f c}}\right) \cdot I_{f c}
$$

Then the hydrogen consumed by the FC is computed using:

$$
\dot{n}_{H 2}^{c o n}=\frac{N_{f c} I_{f c}}{2 F U}
$$

where $F$ is the Faraday constant, and $U$ is the utilization efficiency of hydrogen in the FC.

From the above equations, we can derive that $P_{f c}=f\left(\dot{n}_{H 2}^{c o n}\right)$, where $f($.$) is a nonlinear function. In order to reduce the calcu-$ lation time and obtain a linear model, we use linear regression to simplify this function, without significant loss of model accuracy in the normal operation zones:

$$
\dot{n}_{H 2}^{c o n}=k_{f c} \cdot P_{f c}
$$

where $k_{f c}$ is a constant.

\subsection{Fuel cell degradation model}

The FC operates as the main power source, which means that it will run for a large number of hours, and over time, its performance will decrease. The degradation of the fuel cell must thus be considered [13, 14]. Here, we consider a steady-state lifetime FC model, where the output current is a constant value, which reduces the degradation of fuel cell. As the FC operates as a long term storage system, cycling loads (load changes, start-stop, idling, and high power) will be the main load demands, which will accelerate the degradation of the fuel cell [67]. But in this first planning stage, the future operation states of the fuel cell are unknown, which means that the accelerated factors of degradation are unknown. In other words, the future operation states can only be estimated. The steady state lifetime model is therefore adopted, where it is assumed that the FC will operate at a constant output.
The degradation of the fuel cell causes the voltage drop, which can be represented as:

$$
\Delta V_{f c}=k_{v d} \cdot t_{d a y}
$$

where $\Delta V_{f c}$ is the voltage drop of fuel cell, $t_{\text {day }}$ is the operation duration, $k_{v d}$ is a constant value.

The degradation of the fuel cell mainly influences the resistance $r_{f c}$ [13]. This means that resistance $r_{f c}$ will change as the fuel cell keeps operating. This can be written as:

$$
r_{f c}\left(t_{d a y}\right)=k_{r f c} \cdot k_{v d} \cdot t_{d a y}
$$

where $r_{f c}\left(t_{d a y}\right)$ is the resistance at time $t_{d a y}$, and $k_{r f c}$ is a constant coefficient.

The degradation model of the fuel cell can then be written as:

$$
V_{f c}=\left(E_{O C}-r_{f c}\left(t_{d a y}\right) \cdot i_{f c}-a \cdot \ln \left(i_{f c}\right)-m \cdot e^{n_{0} \cdot i_{f c}}\right) \cdot N_{f c}
$$

With the above degradation model, Fig. 2 can be obtained, which shows the voltage/current characteristic of the fuel cell after different operation durations.

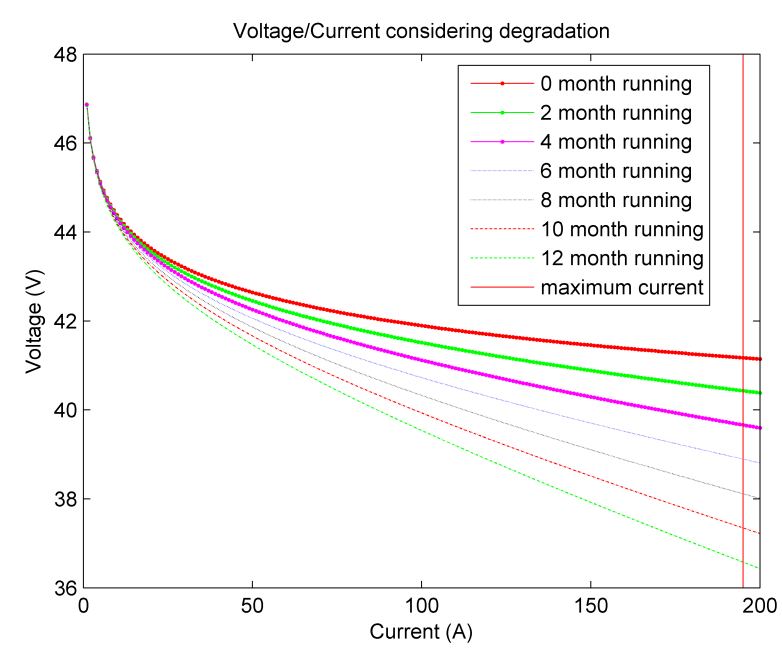

Figure 2: Voltage/current characteristic of a fuel cell after different operationg durations.

From Fig. 2, the relationship between output power and consumed hydrogen considering the degradation model can be obtained:

$$
\dot{n}_{H 2}^{c o n}=k_{f c}\left(t_{d a y}\right) \cdot P_{f c}
$$

where $k_{f c}\left(t_{d a y}\right)$ is the coefficient value in time $t_{d a y}$, derived from current and voltage values.

On the other hand, the degradation of the fuel cell also decreases the maximum output power. As a fuel cell has a maximum output current, with different voltage/current curves, the maximum output power is also different. This can be represented as:

$$
P_{f c}^{\max }\left(t_{d a y}\right)=P_{i n i}^{\max }-k_{f c m} \cdot t_{d a y}
$$

where $P_{f c}^{\max }\left(t_{d a y}\right)$ is the maximum output power at time $t_{d a y}$, $P_{i n i}^{\max }$ is the initial maximum output power, and $k_{f c m}$ is the coefficient. 


\subsection{Electrolyzer model}

An electrolyzer can produce hydrogen from electricity, and this hydrogen is then usually stored in tanks. The characteristic of an electrolyzer can be described as follows [68, 69]:

$$
\begin{aligned}
& V_{e l}=N_{e l} \cdot V_{r e v}+\left(r_{1}+r_{2} \cdot T\right) \cdot \frac{I_{e l}}{A_{e l}} \\
& +\left(s_{1}+s_{2} \cdot T+s_{3} \cdot T^{2}\right) \cdot \log \left(1+\left(t_{1}+\frac{t_{2}}{T}+\frac{t_{3}}{T^{2}}\right) \cdot \frac{I_{e l}}{A_{e l}}\right)
\end{aligned}
$$

where $V_{e l}$ is the voltage of the electrolyzer, $N_{e l}$ the number of cells, $V_{\text {rev }}$ the reversible cell potential, $T$ the temperature and $I_{e l} / A_{e l}\left(A / m^{2}\right)$ the current density. $r_{1}, r_{2}, s_{1}, s_{2}, s_{3}, t_{1}, t_{2}$, and $t_{3}$ are empirical coefficients.

As for the FC, the theoretical production rate of hydrogen in a cell is given by:

$$
\dot{n}_{H 2}^{\text {pro }}=\eta_{F} \frac{N_{e l} I_{e l}}{2 F}
$$

Based on Faradays efficiency, we can obtain the relation between the real production rate of hydrogen and the theoretical one, using:

$$
\eta_{F}=\frac{\left(I_{e l} / A_{e l}\right)^{2}}{f_{1}+\left(I_{e l} / A_{e l}\right)^{2}} f_{2}
$$

where $f_{1}$ and $f_{2}$ are coefficients.

As for the FC, we also linearize the model to obtain:

$$
\dot{n}_{H 2}^{\text {pro }}=k_{e l} \cdot P_{e l}
$$

where $k_{e l}$ is a constant.

\subsection{Electrolyzer degradation model}

Contrary to the FC, the degradation of the electrolyzer will cause the cell voltage to increase [70,71], which can be represented as:

$$
\Delta V_{e l}=k_{v i} \cdot t_{d a y}
$$

where $\Delta V_{e l}$ is voltage increase of the electrolyzer, $t_{d a y}$ is the operation time, and $k_{v i}$ is a constant value.

Electrolyzer degradation mainly influences the resistance $r_{1}$ in equation (12) [71]. This means that resistance $r_{1}$ will change as the electrolyzer continues operating. This can be written as:

$$
r_{1}\left(t_{\text {day }}\right)=k_{\text {rele }} \cdot k_{v i} \cdot t_{\text {day }}
$$

where $r_{1}\left(t_{d a y}\right)$ is the resistance at time $t_{\text {day }}$, and $k_{\text {rele }}$ is a coefficient.

The degradation model of fuel cell can then be written as:

$$
\begin{aligned}
& V_{e l}=N_{e l} \cdot V_{r e v}+\left(r_{1}\left(t_{\text {day }}\right)+r_{2} \cdot T\right) \cdot \frac{I_{e l}}{A_{e l}} \\
& +\left(s_{1}+s_{2} \cdot T+s_{3} \cdot T^{2}\right) \cdot \log \left(1+\left(t_{1}+\frac{t_{2}}{T}+\frac{t_{3}}{T^{2}}\right) \cdot \frac{I_{e l}}{A_{e l}}\right)
\end{aligned}
$$

With the above degradation model, Fig. 3 can be obtained, which shows the voltage/current characteristic of electrolyzer after different operation durations.

Fom Fig. 3, the relationship between input power and produced hydrogen with the degradation model can be obtained:

$$
\dot{n}_{H 2}^{\text {pro }}=k_{e l}\left(t_{d a y}\right) \cdot P_{e l}
$$

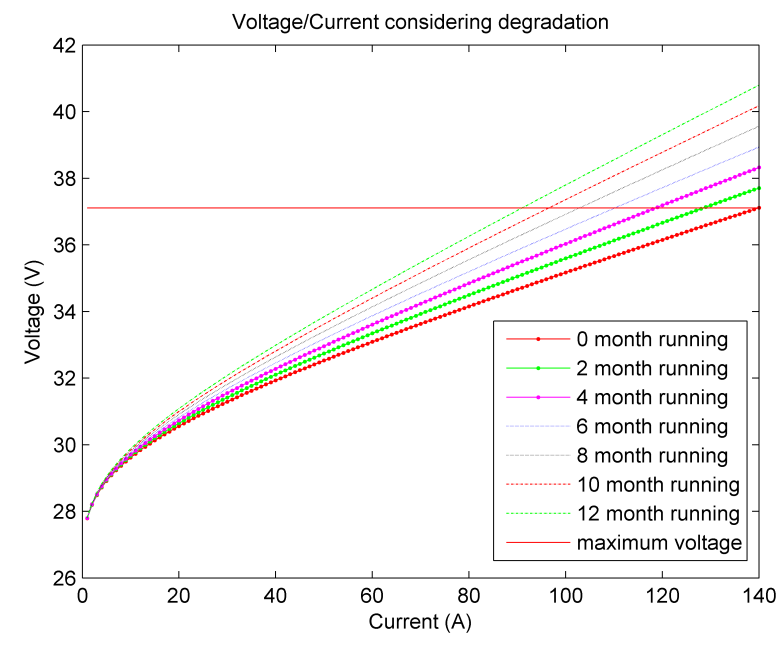

Figure 3: Voltage/current characteristic of an electrolyzer after different operation durations.

where $k_{e l}\left(t_{d a y}\right)$ is the coefficient value at time $t_{\text {day }}$.

On the other hand, the degradation of the electrolyzer also decreases the maximum input power. As the electrolyzer has a maximum input voltage, this means that with different voltage/current curves, the maximum input power will be different. This can be represented as:

$$
P_{\text {ele }}^{\max }\left(t_{\text {day }}\right)=P_{\text {inie }}^{\max }-k_{\text {elem }} \cdot t_{\text {day }}
$$

where $P_{\text {ele }}^{\max }\left(t_{\text {day }}\right)$ is the maximum input power in time $t_{\text {day }}, P_{\text {inie }}^{\text {max }}$ is the initial maximum input power, and $k_{\text {elem }}$ is the coefficient.

\subsection{Hydrogen tank model}

A hydrogen tank is used to store the hydrogen produced by the electrolyzer, as well as to supply hydrogen to the fuel cell. We use the level of hydrogen $(\mathrm{LOH})$ to represent the state of the hydrogen tank:

$$
L O H(t)=L O H(t-\Delta t)+\dot{n}_{H 2}^{p r o} \cdot \Delta t-\dot{n}_{H 2}^{c o n} \cdot \Delta t-L_{H_{2}}(t)
$$

where $L_{H_{2}}(t)$ is the hydrogen load demand. Then, with the law of perfect gases $(P V=n R T)$, the volume of the $H_{2}$ tanks can be calculated.

\subsection{Battery}

We use the state-of-charge (SOC) to represent the state of the battery as follows:

$$
\begin{aligned}
\operatorname{SOC}(t)= & S O C(t-\Delta t) \\
& +\frac{\eta_{c h} \cdot P_{c h}(t) \cdot \Delta t}{C B}-\frac{P_{d i s}(t) \cdot \Delta t}{C B}
\end{aligned}
$$

where $\eta_{c h}$ is the charging efficiency, $P_{c h}(t)$ is the charging power, $P_{d i s}(t)$ is the discharging power, $\Delta t$ is the interval time, and $C B$ is the capacity of the battery. 


\subsection{Battery degradation model}

For the battery, we use the same linear degradation model as for the fuel cell. Calendar and cycling age [72] are the two main factors that cause the degradation of battery. Four models are used to fit the state-of-health (here, the ratio of the current usable capacity to the initial or nominal capacity) of the battery [72]. In addition, the degradation of the battery is also caused by the cycling operation. For example, [73] shows the degradation of the capacity with the number of cycles. Therefore, a linear model is used to describe the degradation of the battery.

As in the first planning stage, the future operation of battery is uknown, it is assumed that the degradation of the battery is linear. Based on the linear model, the remaining capacity of battery in each day can be calculated:

$$
C_{b a}(\text { cycles })=C_{i n i}-\frac{C_{\text {ini }}-C_{\text {last }}}{\text { Cycles }_{\text {max }}} \cdot \text { cycles }
$$

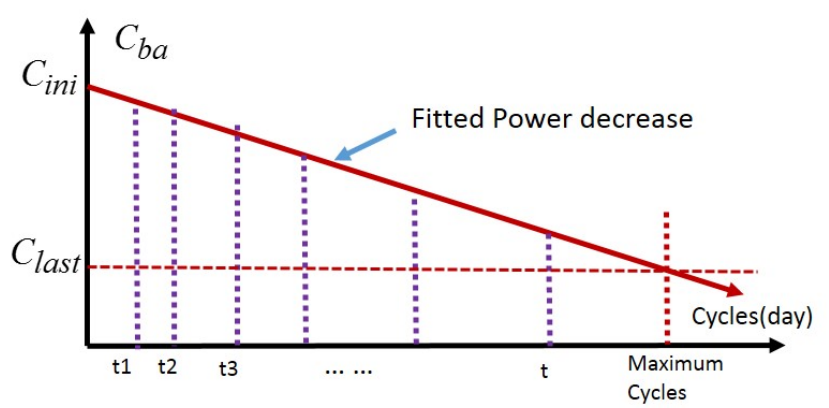

Figure 4: Remaining capacity of battery vs. number of cycles.

\subsection{Thermal components}

We use simple models for the thermal components. A heat boiler uses electricity to produce heat, as follows:

$$
Q_{h b}=\eta_{h b} \cdot P_{h b}
$$

where $P_{h b}$ is the input power, $\eta_{h b}$ the efficiency, and $Q_{h b}$ the output heat.

An air conditioner is used to cool air [74]:

$$
C_{a c}=\eta_{a c} \cdot P_{a c}
$$

where $P_{a c}$ is the input power, $\eta_{a c}$ the efficiency, and $C_{a c}$ the cooling output cooling power.

Similarly, the absorption heat chiller uses heat to produce cooling, so the relation is [74]:

$$
C_{a h c}=\eta_{a h c} \cdot Q_{a h c}
$$

where $Q_{a h c}$ is the input heat, $\eta_{a h c}$ the efficiency, and $C_{a h c}$ the output cooling power.

Finally, the state of the heat storage system is represented by the amount of heat stored [28]:

$$
H S(t)=H S(t-\Delta t)+\eta_{h s}^{c h} \cdot Q_{h s}^{c h}(t) \cdot \Delta t-\frac{Q_{h s}^{d i s}(t)}{\eta_{h s}^{d i s}} \cdot \Delta t
$$

where $H S(t)$ is the stored heat at time $\Delta t . Q_{h s}^{c h}(t)$ and $Q_{h s}^{d i s}(t)$ are the charge and discharge heating power at time $t . \eta_{h s}^{c h}$ and $\eta_{h s}^{d i s}$ are the charge and discharge efficiency, respectively.

\section{UC optimization operation strategy}

After modeling the system, the operation strategy of the microgrid must be described. In this paper, a UC optimization method formed as an MILP is adopted to optimize system operation. UC optimization is based on current and future predicted information to optimize the operating points of each component while minimizing a cost function. In this case, the predicted information corresponds to solar radiation and loads, and the cost function is the total cost (including capital cost, maintenance cost and operation cost).

\subsection{Cost function}

In order to minimize the operation cost, the utilization costs of different components need to be assessed. For the battery storage system (BSS), the utilization cost of charge and discharge are introduced as follows [75]:

$$
B_{\text {cost }}^{\text {ch,dis }}(t)=\frac{C_{b a}^{i n v}}{2 \cdot N_{\text {cycles }}} \cdot\left(P_{c h}(t)+P_{\text {dis }}(t)\right)
$$

where $C_{b a}^{i n v}$ is the investment cost of the battery, and $N_{c y c l e s}$ is the number of cycles over the lifetime.

The hydrogen storage system (HSS) combines an electrolyzer, a fuel cell and hydrogen tanks. As for the BSS, its utilization cost can be computed as follows [75]:

$$
\begin{aligned}
& H_{\text {cost }}^{\text {ele }}(t)=\left(\frac{C_{\text {ele }}^{\text {inv }}}{N_{\text {hours }}^{\text {ele }}}+C_{\text {ele }}^{o \& m}\right) \cdot \delta_{\text {ele }}(t)+C_{\text {ele }}^{\text {startup }} \cdot \Delta \delta_{\text {ele }}(t) \\
& H_{\text {cost }}^{f c}(t)=\left(\frac{C_{f c}^{\text {inv }}}{N_{\text {hours }}^{f c}}+C_{f c}^{\text {o\&m }}\right) \cdot \delta_{f c}(t)+C_{f c}^{\text {startup }} \cdot \Delta \delta_{f c}(t)
\end{aligned}
$$

where $C_{e l e}^{i n v}, C_{f c}^{i n v}$ are the investment costs of the electrolyzer and the fuel cell, $C_{\text {ele }}^{o \& m}$ and $C_{f c}^{o \& m}$ the operation and maintenance costs, and $C_{\text {ele }}^{\text {startup }}$ and $C_{f c}^{\text {startup }}$ the startup costs. Variables $\delta_{\text {ele }}(t)$ and $\delta_{f c}(t)$ are the state of the electrolyzer and the fuel cell. When a unit is on, $\delta_{i}(t)=1, i=\{e l e, f c\}$, otherwise it is set to 0 . Equation $\Delta \delta_{i}(t)=\max \left\{\delta_{i}(t)-\delta_{i}(t-1), 0\right\}, i=\{e l e, f c\}$ represents whether the unit started or not.

We use a similar approach for thermal components. The heat boiler, air conditioner and absoption heat chiller operation costs are given by [76]:

$$
\begin{aligned}
H B_{\text {cost }}(t) & =\frac{C_{h b}^{i n v}}{N_{\text {life }}^{h b}} \cdot P_{h b}(t) \\
A C_{\text {cost }}(t) & =\frac{C_{a c}^{i n v}}{N_{\text {life }}^{a c}} \cdot P_{a c}(t) \\
A H C_{\text {cost }}(t) & =\frac{C_{a h c}^{i n v}}{N_{\text {life }}^{a h c}} \cdot P_{a h c}(t)
\end{aligned}
$$


For the heat storage system, the operation cost is:

$$
H S_{\text {cost }}(t)=\frac{C_{h s}^{i n v}}{N_{l i f e}^{h s}} \cdot\left(Q_{h s}^{c h}(t)+Q_{h s}^{d i s}(t)\right)
$$

\subsection{Operation cost function}

The optimization tries to minimize the overall operation costs over a given horizon of $T$ time steps. The total cost function is then as follows:

$$
\begin{aligned}
C_{o p}=\sum_{t=1}^{T} & \left\{B_{\text {cost }}^{\text {ch,dis }}(t)+H_{\text {cost }}^{\text {ele }}(t)+H_{\text {cost }}^{f c}(t)+a_{1} \cdot H B_{\text {cost }}(t)+\right. \\
& a_{2} \cdot A C_{\text {cost }}(t)+A H C_{\text {cost }}(t)+H S_{\text {cost }}(t) \\
& +\alpha \cdot\left(L S_{\text {cooling }}(t)+L S_{\text {heat }}(t)+L S_{\text {power }}(t)\right. \\
& \left.+\beta \cdot\left(\text { cut }_{P V}(t)+\text { cut }_{\text {solar }}(t)\right)\right\}
\end{aligned}
$$

where $L S_{m}(t)$ with $m=$ \{cooling, heat, power $\}$ are the shed cooling, heat and power loads, and $c u t_{n}(t)$ with $n=\{\mathrm{PV}$, solar $\}$ are the curtailed PV power and solar heating. $\alpha$ and $\beta$ are penalty values for load shedding and curtailed power. When there is excess PV generation, there are four solutions to handle the resulting surplus: using the electrolyzer to store hydrogen, charging the battery, using the heat boiler to store heat, and using the air conditioner to supply cooling demands. The priorities are set as follows: first the electrolyzer, second the battery, then the heat boiler and at last, the air conditioner. Parameters $a_{1}$ and $a_{2}$ are used to adjust the priorities.

\subsection{Constraints}

The stand-alone microgrid is subject to the following constraints, with $i=\{e l, f c\}$ and $j=$ $\{e l, f c$, bach, badis, hb, ac, ahc, hsch, hsdis $\}, Z_{j}(t)=\delta_{j}(t) P_{j}(t)$. Variables $\gamma_{1}^{j}$ and $\gamma_{2}^{j}$ are constant real values used to set the minimum and maximum power range of each component:

$$
\begin{gathered}
\gamma_{1}^{j} P_{j}^{\max } \leq P_{j}(t) \leq \gamma_{2}^{j} P_{j}^{\max } \\
\delta_{j}(t) \cdot \gamma_{1}^{j} P_{j}^{\max } \leq Z_{j}(t) \leq \delta_{j}(t) \cdot \gamma_{2}^{j} P_{j}^{\max } \\
Z_{j}(t) \leq P_{j}(t)-\left(1-\delta_{j}(t)\right) \cdot \gamma_{1}^{j} P_{j}^{\max } \\
Z_{j}(t) \geq P_{j}(t)-\left(1-\delta_{j}(t)\right) \cdot \gamma_{2}^{j} P_{j}^{\max } \\
\delta_{\text {ele }}(t)+\delta_{f c}(t) \leq 1 \\
\delta_{\text {bach }}(t)+\delta_{\text {badis }}(t) \leq 1 \\
\delta_{\text {hsch }}(t)+\delta_{\text {hsdis }}(t) \leq 1
\end{gathered}
$$

Equation (39) means that the fuel cell and the electrolyzer cannot start up at the same time. The BSS and heat storage system also cannot charge and discharge at the same time.

$\Delta \delta_{i}(t)=\max \left\{\delta_{i}(t)-\delta_{i}(t-1), 0\right\}$ can be expressed as $\Delta \delta_{i}(t)=$ $\delta_{i}(t) \cdot\left(1-\delta_{i}(t-1)\right)$.
Then, using [77], the above nonlinear equations system can be transformed into the following linear constraints:

$$
\begin{aligned}
& -\delta_{i}(t)+\Delta \delta_{i}(t) \leq 0 \\
& -\left(1-\delta_{i}(t-1)\right)+\Delta \delta_{i}(t) \leq 0 \\
& \delta_{i}(t)+\left(1-\delta_{i}(t-1)\right)-\Delta \delta_{i}(t) \leq 1
\end{aligned}
$$

In order to limit the startup/shutdown times of the fuel cell and the electrolyzer, the following constraints are added: when a fuel cell or electrolyzer starts up, it continues to run for at least $k_{\text {run }}$ time steps:

$$
\begin{aligned}
& \operatorname{Ind}_{i}(t)=\delta_{i}(t)-\delta_{i}(t-1) \\
& \delta_{i}\left(t: t+k_{\text {run }}\right) \geq \operatorname{Ind}_{i}(t)
\end{aligned}
$$

The power balance equation is written as:

$$
\begin{aligned}
& P V(t)-\operatorname{cut}_{P V}(t)-\left(L_{\text {power }}(t)-L S_{\text {power }}(t)\right)=Z_{\text {ele }}(t) \\
& -Z_{f c}(t)+Z_{\text {bach }}(t)-Z_{\text {badis }}(t)+Z_{a c}(t)+Z_{h b}(t)
\end{aligned}
$$

Similarly, for the heat and cooling balance equations:

$$
\begin{gathered}
Q_{s h}(t)-c u t_{\text {solar }}(t)-\left(L_{\text {heat }}(t)-L S_{\text {heat }}(t)\right)+Q_{f c}(t) \\
+Q_{h b}(t)=Q_{h s c h}(t)-Q_{h s d i s}(t)+Q_{a h c}(t) \\
C_{a c}(t)+C_{a h c}(t)=L_{\text {cooling }}(t)-L S_{\text {cooling }}(t)
\end{gathered}
$$

Finally, for the SOC, LOH and HS constraints:

$$
\begin{aligned}
& S O C_{\text {min }} \leq S O C(t) \leq S O C_{\text {max }} \\
& L O H_{\text {min }} \leq L O H(t) \leq L O H_{\text {max }} \\
& H S_{\text {min }} \leq H S(t) \leq H S_{\text {max }}
\end{aligned}
$$

In summary, for the UC control strategy, the problem can be formulated as:

$$
\begin{aligned}
& \min _{\widetilde{S}}\left\{C_{o p}\right\} \\
& \text { s.t. }(10),(11),(19),(20),(21),(22),(23),(36)-(45)
\end{aligned}
$$

where $\widetilde{S}$ is the set of variables.

\section{Sizing methodology}

Based on the above section, we can describe the power flow in the microgrid system. Our goal is to compute the optimal size value of each component, namely, $N_{P V}, N_{s h}, C B, P_{f c}^{\max }, P_{e l}^{\max }, V_{H_{2}}^{\max }, P_{h b}^{\max }, P_{a c}^{\max }, Q_{a h c}^{\max }, H S_{\max }$. Let set $U$ represent these sizing variables. Then the sizing problem is $\min F(U)$, with $F($.) the total cost function introduced in the following.

In this paper, we use the co-optimization method with an EA [78] to solve the sizing problem, and then MILP to solve the operation problem. The simulation process is shown in Fig. 5:

1. First, $N$ candidate solutions are generated for the GA. 
2. Each of these solutions is then used with the operation problem. The UC MILP optimization is run to solve problem (46). As a one year (8760 hours) MILP optimization would require a large simulation time, we adopt a method based on 12 peak demand days. Each of the 12 days is calculated with the MILP optimization. If no solution is feasible, then a new candidate solution is generated.

3. The GA fitness function value is then computed to determine the total cost of each candidate solution, by calculating (49).

4. The process continues until any stopping criterion is met. Here, an adaptive method is selected. Firstly, if the fitness function values for two consecutive steps are the same, then counter Num is incremented. If Num exceeds a given maximum value (here $N u m^{\max }=30$ ), the simulation stops as the fitness function is not improving anymore. The second criterion is on the number of iterations, for which a maximum number (here $G e n^{\max }=100$ ) is set.

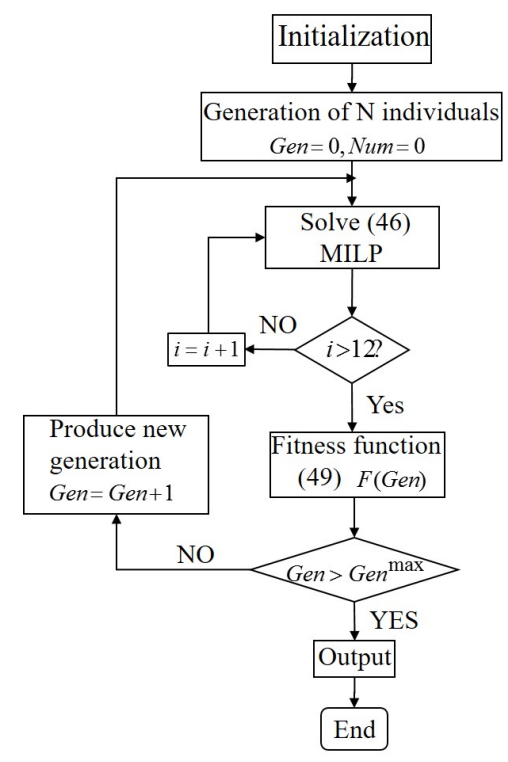

Figure 5: Optimization process outline.

The total capital cost corresponds to the cost of buying the equipment, and is given by:

$$
\begin{aligned}
C_{\text {cap }}=C R F \cdot( & N_{P V} \cdot C_{P V}^{i n v}+N_{s h} \cdot C_{s h}^{i n v}+P_{f c}^{\max } \cdot C_{f c}^{i n v} \\
& +P_{e l}^{\max } \cdot C_{e l e}^{i n v}+V_{H_{2}} \cdot C_{t a n k}^{i n v}+C_{b a t} \cdot C_{b a t}^{i n v} \\
& +P_{h b}^{\max } \cdot C_{h b}^{i n v}+P_{a c}^{\max } \cdot C_{a c}^{i n v}+P_{a h c}^{\max } \cdot C_{a h c}^{i n v} \\
& \left.+H S_{\max } \cdot C_{h s}^{i n v}\right)
\end{aligned}
$$

where $C^{i n v}$ variables represent the prices of each component. $C R F=\frac{r(1+r)^{n_{i n v}}}{(1+r)^{n_{i n v}-1}}$ is the capital recovery factor (CRF) [15], $r$ is the real interest rate and $n_{i n v}$ is the expected life span of the microgrid.

Similarly, the annual maintenance cost is given by:

$$
C_{\mathrm{mnt}}=N_{P V} \cdot C_{P V}^{m n t}+V_{H_{2}} \cdot C_{\text {tank }}^{m n t}+C_{b a t} \cdot C_{b a t}^{m n t}
$$

where $C^{m n t}$ variables represent the annual maintenance costs of the PV, hydrogen tanks and battery components. As the O\&M cost of the FC and the electrolyzer are considered in the operation strategy equations (28) to (30), they are not included in the annual cost. The maintenance cost of the heat boiler, the air conditioner, the absorbtion heat chiller, and the heat storage are neglected.

The total cost function $F($.$) is thus:$

$$
F=C_{\text {cap }}+C_{\text {op }}+C_{\text {mnt }}
$$

Finally, the overall problem can be formulated as:

$$
\begin{aligned}
& \min _{U \in \mathbf{U}}\left\{C_{\text {cap }}+\min _{U^{*}, \widetilde{S}}\left\{C_{\mathrm{op}}\right\}+C_{\mathrm{mnt}}\right\} \\
& \text { s.t. (10), (11), (19), (20), (21), (22), (23), (36) - (45) }
\end{aligned}
$$

In this paper, GA is used to search for the best sizing values.

\section{Simulation results}

\subsection{System setup}

In order to research about the influence of different operation strategies, we set up three different strategies, shown in Table 2. Strategies S1 and S3 are used to compare the influence of minimum startup power of the fuel cell, the electrolyzer and the heat boiler on the sizing results. Strategies S2 and S3 are used to compare different operation durations of the fuel cell and the electrolyzer on the sizing results.

Table 2: Three different operation strategies.

\begin{tabular}{|l|c|c|c|}
\hline Strategy & $\gamma_{1}^{\{f c, e l e\}}$ & $\gamma_{2}^{\{f c, e l e\}}$ & $k_{\text {run }}[h]$ \\
\hline S1 & 0.1 & 1 & 3 \\
S2 & 0.5 & 1 & 5 \\
S3 & 0.5 & 1 & 3 \\
\hline
\end{tabular}

The other main operation parameters are shown in Table 3, where "hb" means heat boiler, "ac" means air conditioner, "ahc" means absorbtion heat chiller, "hy" means hydrogen tanks, and "hs" means heat storage system.

Table 3: Simulation parameters.
\begin{tabular}{|l|c|c|}
\hline Components & $\gamma_{1}$ & $\gamma_{2}$ \\
\hline hb & 0 & 1 \\
ac & 0.1 & 0.9 \\
ahc & 0 & 0.9 \\
\hline Components & $\min$ & $\max$ \\
\hline battery & $S O C_{\min }=0.5$ & $S O C_{\max }=0.9$ \\
hy & OH $_{\min }=1 N . \mathrm{m}^{3}$ & - \\
hs & $H S_{\min }=0$ & - \\
\hline
\end{tabular}

We also set $\alpha=\beta=10^{10}$. The initial state of hydrogen in tanks is $L O H_{\text {ini }}=10^{6} \mathrm{~N} . \mathrm{m}^{3}$. This large value is chosen in order to make sure there is enough hydrogen to run the fuel cell, and will be adjusted in the following. The initial state of the heat 
storage is $H S_{i n i}=3 \cdot 10^{3} \mathrm{kWh}$. The cost parameters are taken from $[16,74,79]$. The degradation parameters are calculated based on [13, 14, 70, 71] and are shown in Table 4. The model is formulated in MATLAB and YALMIP [80], and solved with Gurobi Optimizer. The simulations were run on a computer with an Intel Xeon CPU E3-1220 3.1 GHz, with 16GB RAM.

Table 4: Degradation parameters.
\begin{tabular}{|l|c|c|c|}
\hline$k_{v d}[\mathrm{~V} / \mathrm{h}]$ & $k_{f c m}[\mathrm{~kW} / \mathrm{d}]$ & $k_{v i}[\mathrm{~V} / \mathrm{h}]$ & $k_{\text {elem }}[\mathrm{kW} / \mathrm{d}]$ \\
\hline $3.736 \cdot 10^{-6}$ & 0.002582 & $3 \cdot 10^{-5}$ & 0.004933 \\
\hline
\end{tabular}

Load demand data (for cooling, heat, electric power and hydrogen) and solar radiation are obtainted from a research building, located in Belfort, France. The corresponding profiles (one day average) are shown in Figs. 6 and 7. Hydrogen is used to run fuel cell research experiments. As no direct data is available, heating and cooling loads are calculated based on temperature. In order to avoid long simulation times, we adopt 12 days with one hour data as the input profiles. These days correspond to the electricity load demand peak day, the heating load demand peak day, and the cooling load demand peak day for each season. Then, the sizing results are verified based on a 1-hour rolling horizon simulation, and are adjusted if necessary.

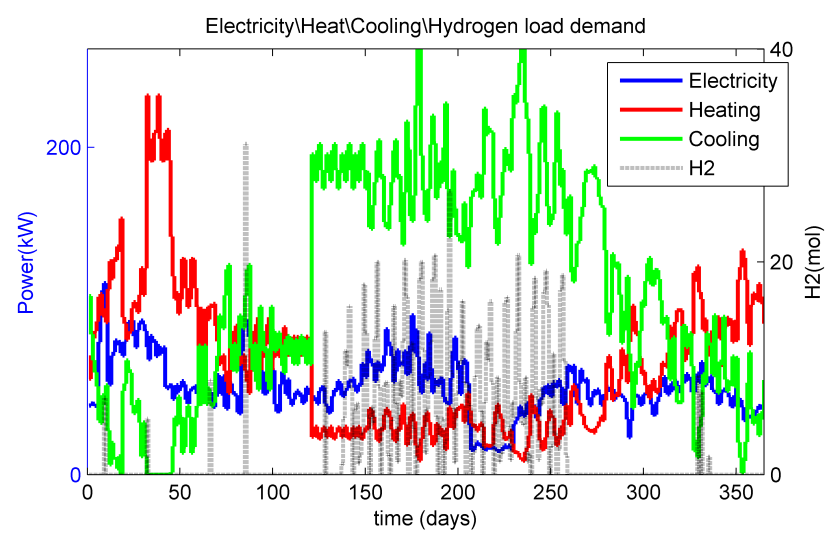

Figure 6: Cooling/heat/electricity demand (one day average).

\subsection{GA-based sizing results}

GA [78] is based on the natural selection process similar to biological evolution. It uses tools such as mutations, crossover and selection to generate candidate solutions. In our simulation, the population is 20 , and the maximum number of iterations is 100. Each candidate solution gives the sizing values of each component. With it, the MILP operation is run, and based on the results, the population is updated.

The optimal size values shown in Table 5 are obtained. Here $\Delta V_{H_{2}}=\max \left\{\Delta V_{H_{2}}^{r d}\right\}, r d=\{1, \ldots, 12\}$, where $r d$ represents the 12 days, and $\Delta V_{H_{2}}^{r d}=V_{\max }^{r d}-V_{\min }^{r d}$ represents the hydrogen volume change in tanks in the $r d^{\text {th }}$ day. Similarly, $\Delta H S=$ $\max \left\{\Delta H S^{r d}\right\}, r d=\{1, \ldots, 12\}, r d$ represents the 12 days, and $\Delta H S^{r d}=H S_{\max }^{r d}-H S_{\min }^{r d}$ represents the heat power change in the heat storage system in the $r d^{\text {th }}$ day. The hydrogen energy

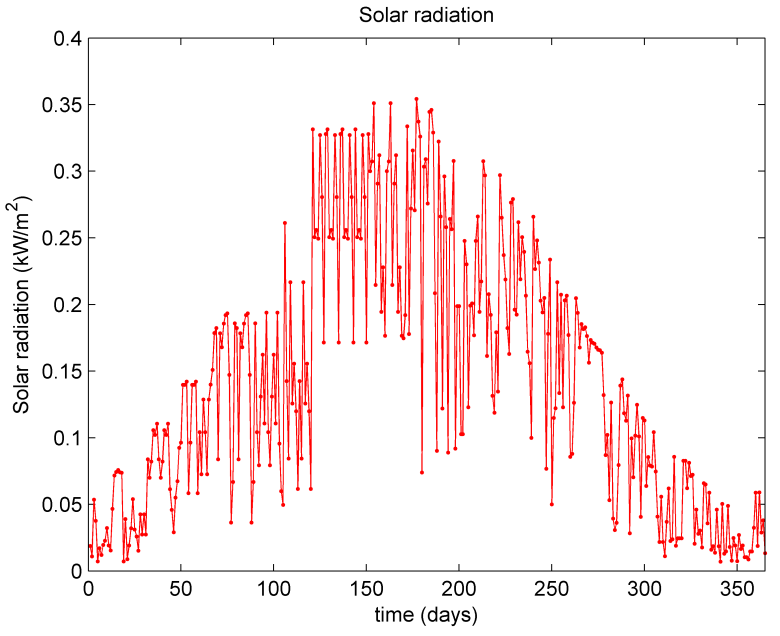

Figure 7: Solar radiation (one day average).

can be expressed in another way: for S1, the hydrogen volume can operate the fuel cell at $100 \mathrm{~kW}$ for 24.9 hours; for $\mathrm{S} 2$, the duration changes to 28.5 hours; and for S3, to 44.6 hours.

The cost results are shown in Table 6. Here, $C_{\text {total }}^{*}$, $C_{o p}^{*}$ represent real cost of the system, namely, $C_{o p}^{*}=$ $\sum_{\text {day }=1}^{12} \sum_{t=1}^{T}\left\{B_{\text {cost }}^{\text {ch,dis }}(t)+H_{\text {cost }}^{\text {ele }}(t)+H_{\text {cost }}^{f c}(t)+\alpha \cdot\left(L S_{\text {cooling }}(t)+\right.\right.$ $\left.\left.L S_{\text {heat }}(t)+L S_{\text {power }}(t)\right)+\beta \cdot\left(\operatorname{cut}_{P V}(t)+\operatorname{cut}_{\text {solar }}(t)\right)\right\}$ (operation cost of heat boiler, air conditioner, absorption heat chiller and heat storage are not considered), $C_{\text {total }}^{*}=C_{c a p}+C_{o p}^{*}+C_{m n t}$.

It can be observed that with different operation strategies, the sizing value of each component is different. In strategy S2, the minimum start power of the fuel cell and the electrolyzer is set to be $50 \%$ of their maximum power, and the minimum run time of the fuel cell and the electrolyzer is 5 hours. These constraints are strict and must be satisfied in the optimization process, leading to a smaller fuel cell, a larger PV and a larger electrolyzer. In strategies S2 and S3, larger PV, electrolyzer, hydrogen tanks and battery are needed, leading to larger capital costs.

Comparing these three operation strategies, we find that if the operation conditions of the HSS are limited (in order to reduce its degradation), the capital cost of the related auxiliary system increases, and the lifetime of the HSS also increases. On the contrary, if the limitations on operation conditions of the HSS are not strict, which means that the HSS can operate in most conditions, the related auxiliary system is smaller, but the life time of HSS also decreases.

Based on the above sizing value, the scheduling results are obtained by running the MILP algorithm. The MILP scheduling is run for one day (electricity peak load demand day in summer) with strategy S2. Scheduling results are shown in Fig. 8, which shows the electric power schedule. During the day, a large surplus PV output can be observed. This may show that the number of PV panels is too large (a smaller value may be more appropriate), but as our simulation is based on 12 days, this means that simulation results must be satisfied for all 12 days, so the number of PV panels is chosen from the global view. We observe that the HSS is the main storage system (the 
Table 5: Sizing results.

\begin{tabular}{ccccccccccc}
\hline Strategy & $N_{P V}$ & $P_{f c}^{\max }[\mathrm{kW}]$ & $P_{e l}^{\max }[\mathrm{kW}]$ & $\Delta V_{H_{2}}\left[\mathrm{~N} \cdot \mathrm{m}^{3}\right]$ & $C_{b a t}[\mathrm{kWh}]$ & $N_{s h}\left[\mathrm{~m}^{2}\right]$ & $P_{h b}^{\max }$ & $\Delta H S[\mathrm{kWh}]$ & $P_{a c}^{\max }$ & $Q_{a h c}^{\max }$ \\
\hline S1 & 121 & 272 & 396 & 1065 & 383 & 45 & 346 & 3000 & 117 & 1207 \\
S2 & 206 & 114 & 584 & 1220 & 659 & 36 & 123 & 3000 & 129 & 3815 \\
S3 & 327 & 131 & 690 & 1903 & 735 & 43 & 283 & 3000 & 159 & 686 \\
\hline
\end{tabular}

\begin{tabular}{|l|c|c|c|}
\multicolumn{5}{|c}{ Table 6: Cost results. } \\
\hline Strategy & $C_{\text {total }}^{*}[€]$ & $C_{\text {cap }}[€]$ & $C_{o p}^{*}[€]$ \\
\hline S1 & $4.0683 \mathrm{e}+05$ & $3.6766 \mathrm{e}+05$ & $3.9171 \mathrm{e}+04$ \\
S2 & $9.6424 \mathrm{e}+05$ & $4.7911 \mathrm{e}+05$ & $4.8513 \mathrm{e}+05$ \\
S3 & $1.2729 \mathrm{e}+06$ & $5.3004 \mathrm{e}+05$ & $7.4290 \mathrm{e}+05$ \\
\hline
\end{tabular}

fuel cell outputs power at night and the electrolyzer consumes the most power in the day time), with slow variations in output, while the BSS serves as an auxiliary storage system, with shorter and more dynamic charge and discharge periods. The heat boiler and the air conditioner also operate to transfer electricity to heating and cooling power. The fuel cell generates more electricity than the electric load demand, in order to supply the heating and cooling loads.

Fig. 9 shows the heating power schedule. During the night, the fuel cell heating and the heat storage system supply most of the heating load demand, and the absorption heat chiller uses heat to serve the cooling load. During the day, the surplus heating power is stored in the heat storage system and is transferred to cooling load using the AHC. The heat boiler uses electricity to heat water, which can be stored or used in the absorption heat chiller. The fuel cell also generates heat water which can be transferred to rooms through pumps. Similarly, Fig. 10 shows the cooling power schedule. The absorption heat chiller and the air conditioner supply all the cooling load.

From the scheduling results, we can see that when there is no PV power output and solar heat output (at night), the fuel cell provides energy for the whole system. It provides electricity to the electric load demand, to the air conditioner to serve the cooling load, and collects heat power to serve the heat load. The heat storage tank provides heating power to the heat load. When there is surplus energy from the PV panels and the solar heating system (during the day), the electrolyzer is used as the main source to consume electricity by producing hydrogen. The heat boiler is also used to consume electricity by producing heat stored in heat tanks.

Regarding storage, Fig. 11 shows the change in $\mathrm{LOH}$ and stored heat, and Fig. 12 the change of SOC. It shows that when there is no PV output, the fuel cell produces power to supply the electric load, and the heat storage tanks provide heat to the heat demand. When there is enough PV output, surplus PV power output and solar heat output are stored in hydrogen tanks and heat tanks, respectively.

\subsection{1-hour rolling horizon simulation}

In order to verify the optimal sizing results, a 1-hour rolling horizon simulation is run. This simulation repeats the 1-hour

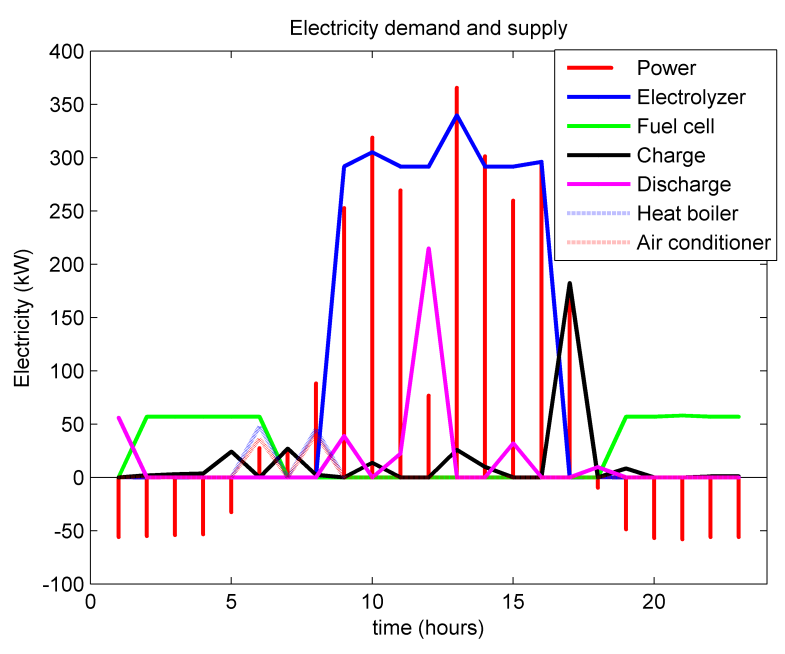

Figure 8: Strategy S2, electric power schedule (Power means PV outputs minus electricity load demand; charge/discharge curves are for the battery).

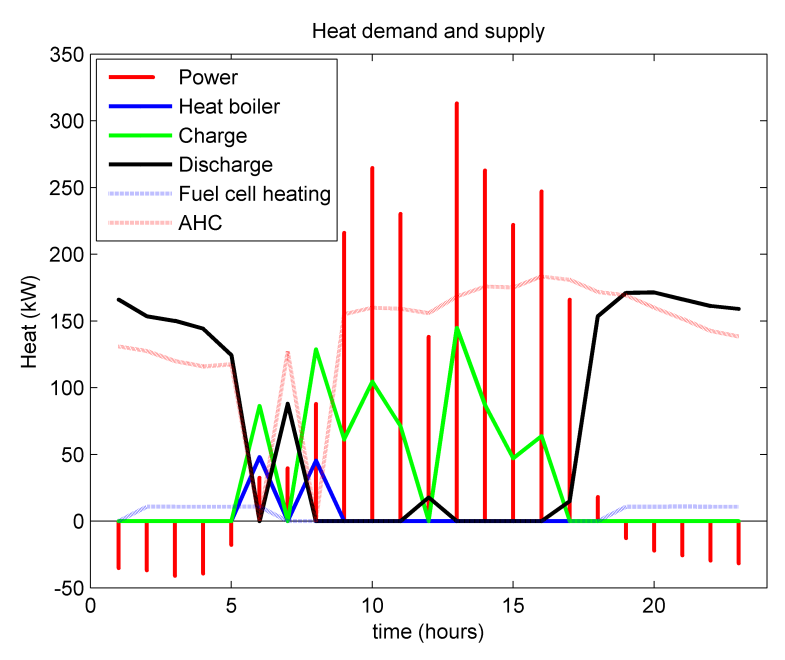

Figure 9: Strategy S2, heating power schedule (Power means solar outputs minus heat load demand; charge/discharge curves are for the heat storage system).

one day UC scheduling for 365 days. Strategy S2 is adopted. We only use 12 days as the input data to obtain the optimal sizing results. In the rolling horizon simulation, the optimization window moves from the current day to the next day, and then repeats until the last day. So the state of the hydrogen tanks and the heat storage system are based on the previous simulation results. To determine the volume of the hydrogen tanks and the heat storage system, we adjust the initial value to a large value. With this new value, the rolling horizon simulation is 


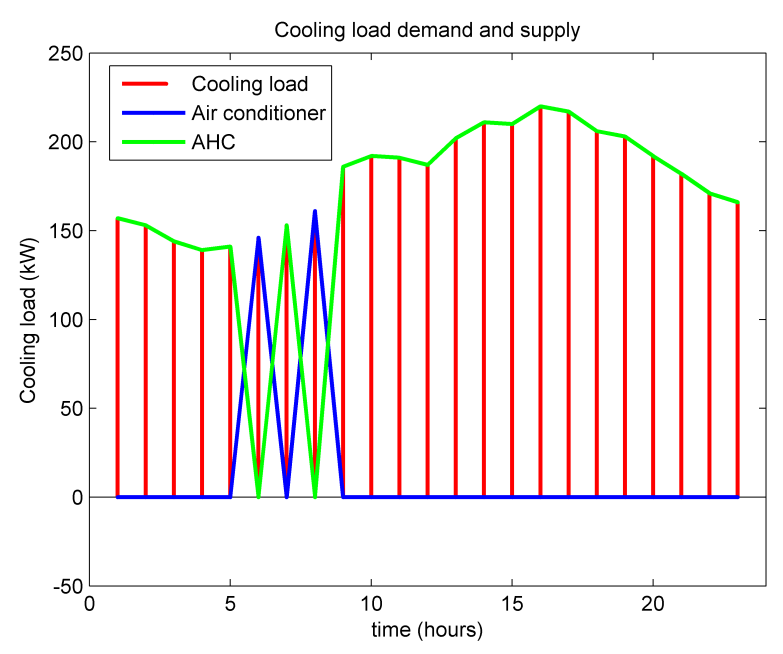

Figure 10: Strategy S2, cooling power schedule.

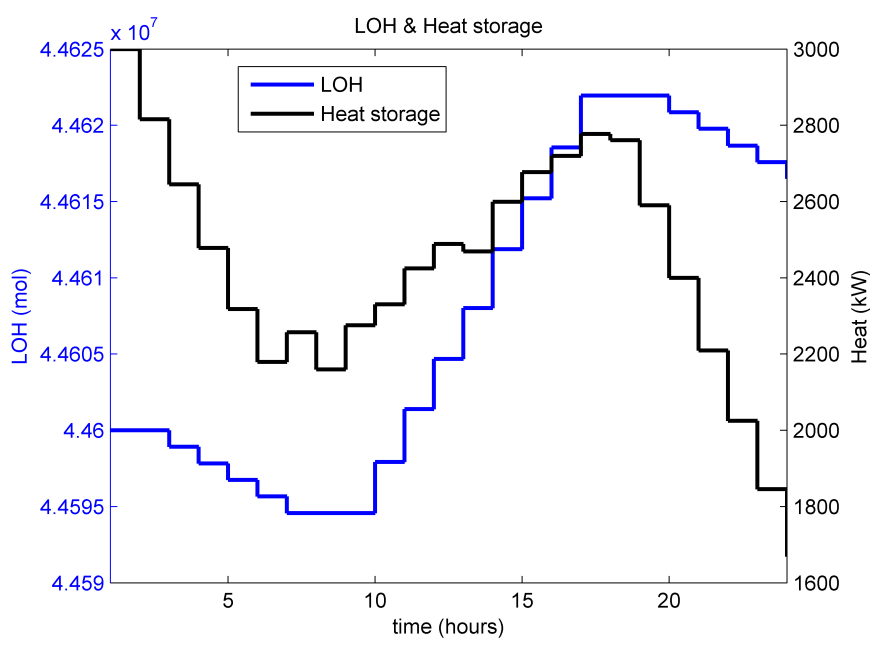

Figure 11: LOH and stored heat.

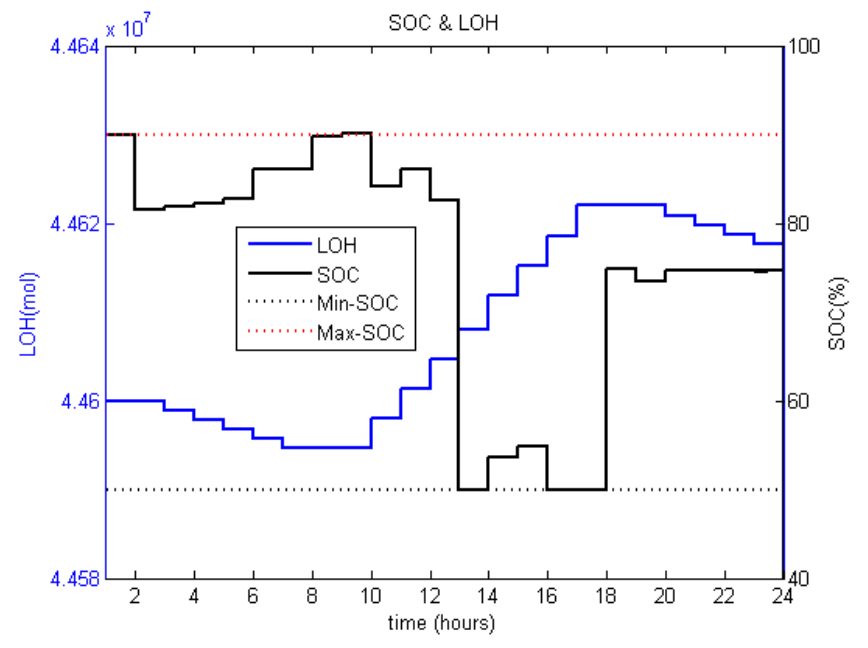

Figure 12: $\mathrm{LOH}$ and SOC. run, and the results are shown in Fig. 13. From Fig. 13, we can see that load shedding and curtailed power occur, which means that these sizing values must be adjusted. Firstly, we adjust the sizing value of the heat boiler to be $123+209=332 \mathrm{~kW}$, as from Table 5, in the second row, we know that the sizing value of the heat boiler is $123 \mathrm{~kW}$, and from Fig. 13, we know that the maximum heating shedding power is $209 \mathrm{~kW}$. This means that the curtailed PV power and more fuel cell output power can be transferred to heat. Then, we adjust the fuel cell capacity to satisfy the heat boiler demand: $114+209 / 0.9=347$ $\mathrm{kW}$, as from Table 5, in the second row, we know that the sizing value of the fuel cell is $114 \mathrm{~kW}$, and the efficiency of the heat boiler is 0.9 . With these new sizing values, the 1 -hour rolling horizon simulation results are shown in Figs. 14, 15, 16, and 17 . We can then calculate the volume of hydrogen tanks: $\max (L O H)-\min (L O H)=141,270 \mathrm{~N} \cdot \mathrm{m}^{3}$. If we do not consider the degradation of the fuel cell, these large amounts of hydrogen can serve a fuel cell operating at $200 \mathrm{~kW}$ for 1,750 hours. For the heat storage system, we obtain $\max (h t)-\min (h t)=4,968$ kWh.After this adjustment, the capital cost of the whole system is $2.2616 \mathrm{e}+06$. The large volume of the hydrogen tanks leads to this large capital cost.
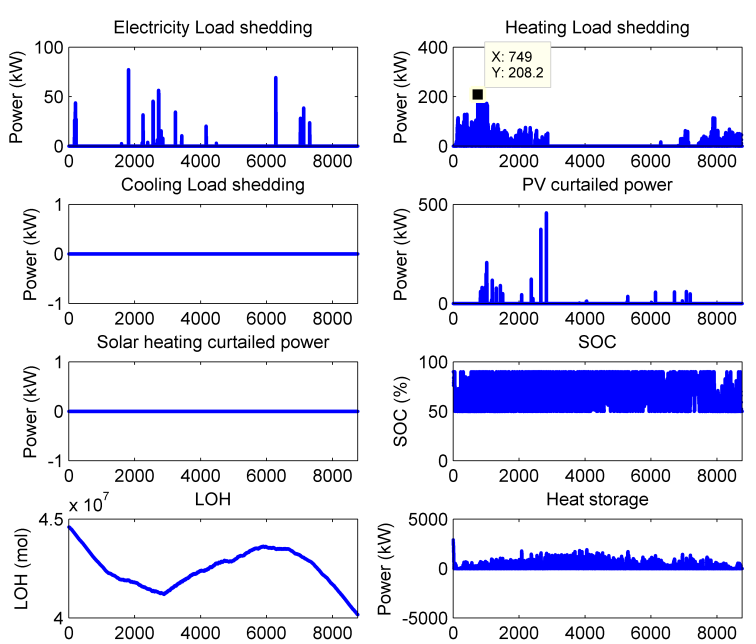

Figure 13: 1-hour rolling horizon simulation.

\subsection{Influence of the degradation of the fuel cell, the elec- trolyzer and battery}

In this section, the degradation models of the fuel cell, the electrolyzer and battery are considered. In this paper, 12 days are used as the input profile, and if we consider the degradation of the fuel cell, the electrolyzer and the battery, the maximum output power of the fuel cell, the maximum input power of the electrolyzer, the consumed hydrogen in fuel cell, the produced hydrogen in the electrolyzer, the remaining capacity of battery will all be different in these 12 days.

Based on equation (10) and (11), we can calculate the new parameters for the fuel cell consumed hydrogen and the maximum output power in $t_{d a y}$. For the electrolyzer, the new param- 


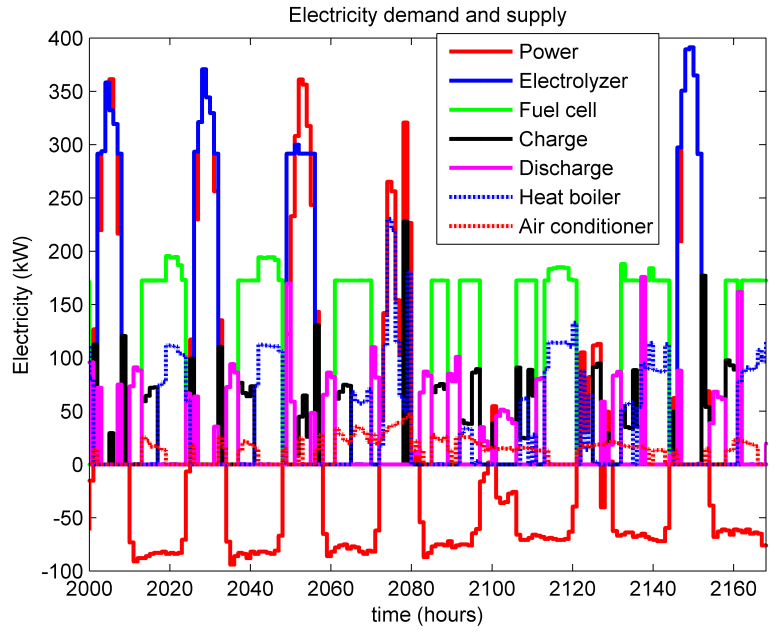

Figure 14: 1-hour rolling horizon simulation, electric power schedule (20002168h).

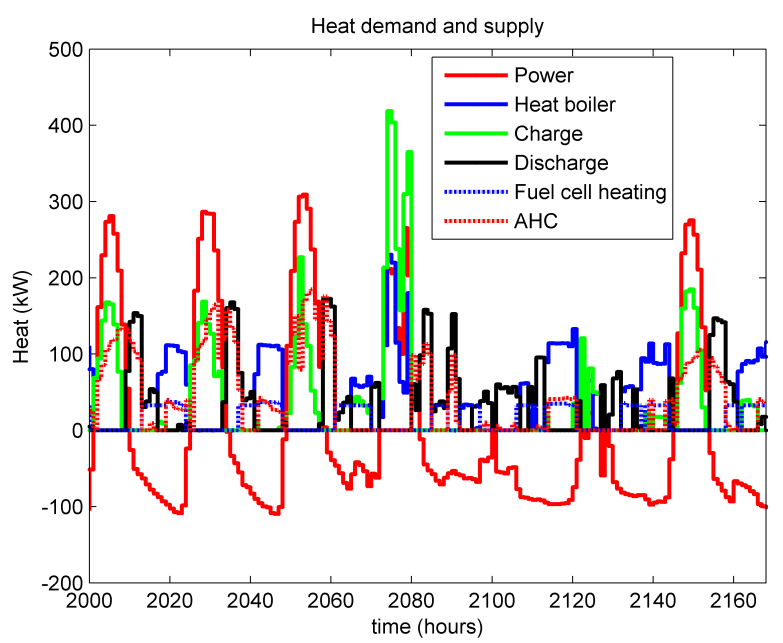

Figure 15: 1-hour rolling horizon simulation, heat power schedule (20002168h).

eters are updated based on (19) and (20). For the battery, the remaining capacity in each day is updated based on (23).

Then the UC optimization problem can be formed as problem (46), and the overall problem is (50). We adopt strategy S1. The simulation results are shown in Table 7. Degall means that the degradation of the fuel cell, the electrolyzer and the battery is considered. Deg means considering the degradation of fuel cell and electrolyzer. We can see that in case Deg, due to the degradation of the fuel cell, a larger capacity of fuel cell is needed to satisfy the load demand; a larger heat boiler and air conditioner are needed to transfer the PV output power to heat or cooling due to the degradation of the electrolyzer. Then, we consider the degradation of the battery with case $D e g_{\text {all }}$. We can see that the capacity of the battery will increase, also for the capacity of the fuel cell and the electrolyzer, with the larger electrolyzer, then the capacity of the heat boiler and the air conditioner is decreased compared to case Deg. The cost results are shown

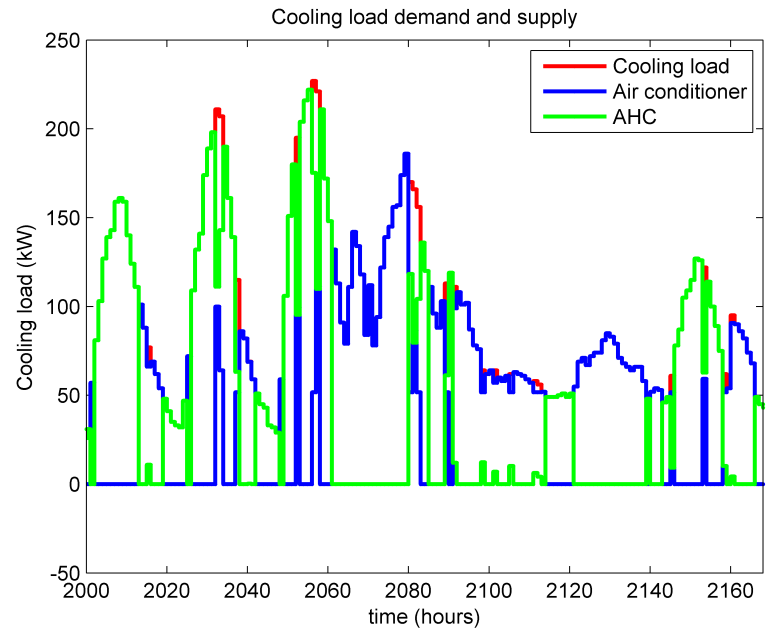

Figure 16: 1-hour rolling horizon simulation, cooling power schedule (20002168h).
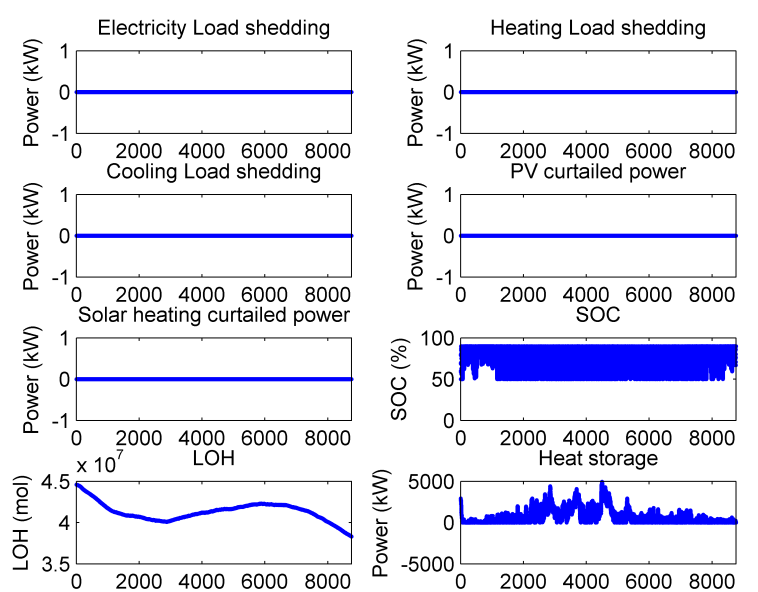

Figure 17: 1-hour rolling horizon simulation.

in Table 8. We can see that in case Deg, the operation cost is smaller. This is because the HSS operates more times (because of the larger capacity of the fuel cell), and the utilization cost of the HSS is much smaller, leading to lower operation costs. In case $D g_{\text {all }}$, due to the large capacity of the storage system, the capital cost of the microgrid is also increased.

\subsection{Influence of uncertainty}

The forecasting errors on PV output and load demand influence the power flow on the whole system, as well as the sizing results of the components. In this section, we adopt a robust method to research about the influence of uncertainty. We use the upper bound and lower bound to represent the uncertainty. $\overparen{P_{P V}(t)}, \widehat{L_{\text {power }}(t)}, \widehat{L_{\text {heat }}(t)}, \widehat{L_{\text {cooling }}(t)}, \widehat{L_{H_{2}}(t)}$ and $E r_{P V}, E r_{\text {power }}, E r_{\text {heat }}, E r_{\text {cooling }}, E r_{H_{2}}$ are used to represent the actual values and error bounds of PV output, solar heating output, electric load demand, heating load demand, cooling 
Table 7: Sizing results considering degradation of the fuel cell, the electrolyzer and the battery.

\begin{tabular}{ccccccccccc}
\hline & $N_{P V}$ & $P_{f c}^{\max }[\mathrm{kW}]$ & $P_{e l}^{\max }[\mathrm{kW}]$ & $\Delta V_{H_{2}}\left[\mathrm{~N} . \mathrm{m}^{3}\right]$ & $C_{b a t}[\mathrm{kWh}]$ & $N_{s h}\left[\mathrm{~m}^{2}\right]$ & $P_{h b}^{\max }$ & $\Delta H S_{\max }[\mathrm{kWh}]$ & $P_{a c}^{\max }$ & $Q_{a h c}^{\max }$ \\
\hline Degall & 224 & 498 & 540 & 1159 & 843 & 43 & 200 & 3000 & 148 & 542 \\
Deg & 103 & 409 & 385 & 1087 & 101 & 48 & 671 & 3000 & 843 \\
S1 & 121 & 272 & 396 & 1065 & 383 & 45 & 346 & 3000 & 117 & 1207 \\
\hline
\end{tabular}

Table 8: Cost results considering degradation of the fuel cell and the electrolyzer.

\begin{tabular}{|l|c|c|c|}
\hline Strategy & $C_{\text {total }}^{*}[€]$ & $C_{\text {cap }}[€]$ & $C_{o p}^{*}[€]$ \\
\hline Deg all & $7.8660 \mathrm{e}+05$ & $5.3978 \mathrm{e}+05$ & $2.4682 \mathrm{e}+05$ \\
Deg & $4.0172 \mathrm{e}+05$ & $3.8183 \mathrm{e}+05$ & $1.9887 \mathrm{e}+04$ \\
S1 & $4.0683 \mathrm{e}+05$ & $3.6766 \mathrm{e}+05$ & $3.9171 \mathrm{e}+04$ \\
\hline
\end{tabular}

load demand, and hydrogen load demand respectively. The actual values can be represented as:

$$
\begin{aligned}
& \overparen{P_{P V}(t)}=P_{P V}(t) \pm P_{P V}(t) \cdot E r_{P V}, \\
& \widetilde{L_{\text {power }}(t)}=L_{\text {power }}(t) \pm L_{\text {power }}(t) \cdot E r_{\text {power }}, \\
& \widetilde{L_{\text {heat }}(t)}=L_{\text {heat }}(t) \pm L_{\text {heat }}(t) \cdot E r_{\text {heat }}, \\
& \widetilde{L_{\text {cooling }}(t)}=L_{\text {cooling }}(t) \pm L_{\text {cooling }}(t) \cdot E r_{\text {cooling }}, \\
& \widetilde{L_{H_{2}}(t)}=L_{H_{2}}(t) \pm L_{H_{2}}(t) \cdot E r_{H_{2}}
\end{aligned}
$$

Two cases are defined in Fig. 18. The worst case (the case where the difference between the PV output and the load is the largest) is when the PV output is equal to the upper bound value, and the load is equal to the lower bound value; or when the PV output is equal to the lower bound value, the load is equal to the upper bound value. For the best case (the case where the difference between the PV output and the load is the lowest), the opposite is used.

If the sizing results can satisfy the worst and best cases, then others cases can also be satisfied by the obtained sizing results. This means that the worst and best case data must be used to run the co-optimization method and obtain the sizing results. Table 9 shows the sizing results when $E r_{P V}=E r_{\text {power }}=E r_{\text {heat }}=$ $E r_{\text {cooling }}=E r_{H_{2}}=0.1$. Table 10 shows the cost results. For the worst-case, the HSS is used frequently because it is cheaper, so larger hydrogen tanks are needed. For the best case, the BSS is used frequently due to limitations of the HSS (minimum startup power and continuous running time), so more BSS capacity is needed. For these two cases, a larger heat storage system is needed to handle the uncertainty.

\section{Conclusion}

In this paper, we introduced a co-optimization method to size the components of a renewable energy based stand-alone microgrid which combines cooling, heat, electric power and hydrogen loads. The UC optimization method is used for defining the operation strategy, which aims at minimizing the operation cost through an MILP algorithm. A GA is used to compute

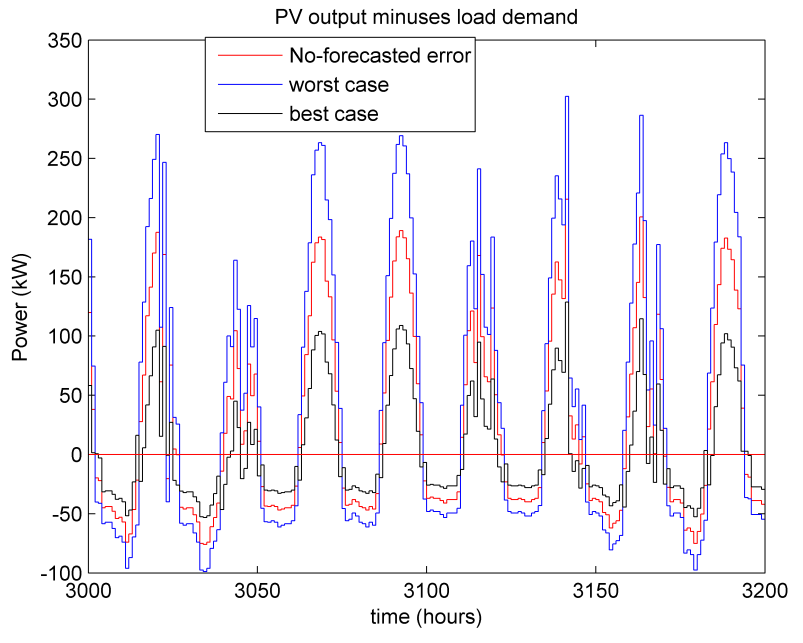

Figure 18: PV output minus load demand

the sizing value of each component, aiming to minimize the total cost. Three operation strategies are compared, which show that sizing values are different with different strategies. Then a 1-hour rolling horizon simulation is used to adjust the sizing values of several components. The degradation of the fuel cell, the electrolyzer and the battery is also considered and shows that the sizing values of the fuel cell and the battery increases when considering the degradation. Uncertainty on PV output and load demand is addressed using robust optimization, and results show that larger volumes of hydrogen tanks and heat storage are needed to tackle these uncertainty factors. This cooptimization method is useful to size complex islanded microgrids, and results show that the optimal size value and operation algorithms are capable of scheduling multiple components and managing flows from different natures (heat/cooling, electricity and hydrogen).

\section{References}

[1] Y. Wang, C. Chen, J. Wang, R. Baldick, Research on resilience of power systems under natural disasters - a review, IEEE Transactions on Power Systems 31 (2) (2016) 1604-1613. doi:10.1109/TPWRS.2015.2429656.

[2] C. Chen, J. Wang, F. Qiu, D. Zhao, Resilient distribution system by microgrids formation after natural disasters, IEEE Transactions on Smart Grid 7 (2) (2016) 958-966. doi:10.1109/TSG.2015.2429653.

[3] D. Wu, R. Wang, Combined cooling, heating and power: a review, progress in energy and combustion science 32 (5) (2006) 459-495.

[4] M. Liu, Y. Shi, F. Fang, Combined cooling, heating and power systems: A survey, Renewable and Sustainable Energy Reviews 35 (2014) 1-22.

[5] W. Gu, Z. Wu, R. Bo, W. Liu, G. Zhou, W. Chen, Z. Wu, Modeling, planning and optimal energy management of combined cooling, heating 
Table 9: Sizing results considering uncertainty. The worst case is defined as the case where the difference between PV output and load is the largest, and the lowest for the best case.

\begin{tabular}{ccccccccccc}
\hline Strategy & $N_{P V}$ & $P_{f c}^{\max }[\mathrm{kW}]$ & $P_{e l}^{\max }[\mathrm{kW}]$ & $\Delta V_{H_{2}}\left[\mathrm{~N} \cdot \mathrm{m}^{3}\right]$ & $C_{b a t}[\mathrm{kWh}]$ & $N_{s h}\left[\mathrm{~m}^{2}\right]$ & $P_{h b}^{\max }$ & $\Delta H S_{\max }[\mathrm{kWh}]$ & $P_{a c}^{\max }$ & $Q_{a h c}^{\max }$ \\
\hline Worst case & 109 & 169 & 307 & 1199 & 437 & 105 & 323 & 9072 & 81 & 531 \\
Best case & 107 & 191 & 247 & 952 & 652 & 124 & 324 & 8219 & 337 & 2728 \\
S1 & 121 & 272 & 396 & 1065 & 383 & 45 & 346 & 3000 & 117 & 1207 \\
\hline
\end{tabular}

Table 10: Cost results considering uncertainty.

\begin{tabular}{|l|c|c|c|}
\hline Strategy & $C_{\text {total }}^{*}[€]$ & $C_{c a p}[€]$ & $C_{o p}^{*}[€]$ \\
\hline Worst case & $3.9060 \mathrm{e}+05$ & $3.7248 \mathrm{e}+05$ & $1.8123 \mathrm{e}+04$ \\
Best case & $4.5288 \mathrm{e}+05$ & $4.2616 \mathrm{e}+05$ & $2.6729 \mathrm{e}+04$ \\
S1 & $4.0683 \mathrm{e}+05$ & $3.6766 \mathrm{e}+05$ & $3.9171 \mathrm{e}+04$ \\
\hline
\end{tabular}

and power microgrid: A review, International Journal of Electrical Power \& Energy Systems 54 (2014) 26-37.

[6] A. L. Facci, V. Cigolotti, E. Jannelli, S. Ubertini, Technical and economic assessment of a sofc-based energy system for combined cooling, heating and power, Applied Energy.

[7] P. Kazempoor, V. Dorer, F. Ommi, Evaluation of hydrogen and methanefuelled solid oxide fuel cell systems for residential applications: system design alternative and parameter study, international journal of hydrogen energy 34 (20) (2009) 8630-8644.

[8] L. B. Jaramillo, A. Weidlich, Optimal microgrid scheduling with peak load reduction involving an electrolyzer and flexible loads, Applied Energy 169 (2016) 857-865.

[9] G. Cau, D. Cocco, M. Petrollese, S. K. Kær, C. Milan, Energy management strategy based on short-term generation scheduling for a renewable microgrid using a hydrogen storage system, Energy Conversion and Management 87 (2014) 820-831.

[10] P. Mancarella, Mes (multi-energy systems): An overview of concepts and evaluation models, Energy 65 (2014) 1-17.

[11] B. Li, R. Roche, A. Miraoui, System resilience improvement using multiple energy supply systems under natural disasters, in: Industrial Electronics Society, IECON 2016-42nd Annual Conference of the IEEE, IEEE, 2016, pp. 3912-3917.

[12] R. P. Menon, M. Paolone, F. Maréchal, Study of optimal design of polygeneration systems in optimal control strategies, Energy 55 (2013) 134141.

[13] J. Li, Z. Hu, L. Xu, M. Ouyang, C. Fang, J. Hu, S. Cheng, H. Po, W. Zhang, H. Jiang, Fuel cell system degradation analysis of a chinese plug-in hybrid fuel cell city bus, International Journal of Hydrogen Energy 41 (34) (2016) 15295-15310.

[14] A. H. Mamaghani, B. Najafi, A. Casalegno, F. Rinaldi, Predictive modelling and adaptive long-term performance optimization of an ht-pem fuel cell based micro combined heat and power (chp) plant, Applied Energy.

[15] A. Maleki, F. Pourfayaz, Optimal sizing of autonomous hybrid photovoltaic/wind/battery power system with lpsp technology by using evolutionary algorithms, Solar Energy 115 (2015) 471-483.

[16] B. Li, R. Roche, A. Miraoui, Microgrid sizing with combined evolutionary algorithm and milp unit commitment, Applied Energy 188 (2017) $547-562$.

[17] L. Meng, E. R. Sanseverino, A. Luna, T. Dragicevic, J. C. Vasquez, J. M. Guerrero, Microgrid supervisory controllers and energy management systems: A literature review, Renewable and Sustainable Energy Reviews 60 (2016) 1263-1273.

[18] Z. Bao, Q. Zhou, Z. Yang, Q. Yang, L. Xu, T. Wu, A multi time-scale and multi energy-type coordinated microgrid scheduling solutionpart i: Model and methodology, IEEE Transactions on Power Systems 30 (5) (2015) 2257-2266.

[19] Z. Luo, Z. Wu, Z. Li, H. Cai, B. Li, W. Gu, A two-stage optimization and control for cchp microgrid energy management, Applied Thermal Engineering.

[20] S. Mashayekh, M. Stadler, G. Cardoso, M. Heleno, A mixed integer linear programming approach for optimal der portfolio, sizing, and placement in multi-energy microgrids, Applied Energy 187 (2017) 154-168.

[21] S. Jayasekara, S. Halgamuge, A review on optimization strategies of combined cooling heating and power generation, in: 2012 IEEE 6th International Conference on Information and Automation for Sustainability, IEEE, 2012, pp. 302-307.

[22] F. Fang, Q. H. Wang, Y. Shi, A novel optimal operational strategy for the cchp system based on two operating modes, IEEE Transactions on Power Systems 27 (2) (2012) 1032-1041.

[23] K. Kavvadias, A. Tosios, Z. Maroulis, Design of a combined heating, cooling and power system: Sizing, operation strategy selection and parametric analysis, Energy Conversion and Management 51 (4) (2010) 833845.

[24] L. Chang, G. Weng, J. Hu, M. Mao, Operation and configuration optimization of a cchp system for general building load, in: Power Electronics and Motion Control Conference (IPEMC-ECCE Asia), 2016 IEEE 8th International, IEEE, 2016, pp. 1799-1805.

[25] G. Kyriakarakos, D. D. Piromalis, A. I. Dounis, K. G. Arvanitis, G. Papadakis, Intelligent demand side energy management system for autonomous polygeneration microgrids, Applied Energy 103 (2013) 39-51.

[26] B. Mohammadi-Ivatloo, M. Moradi-Dalvand, A. Rabiee, Combined heat and power economic dispatch problem solution using particle swarm optimization with time varying acceleration coefficients, Electric Power Systems Research 95 (2013) 9-18.

[27] M. Basu, Artificial immune system for combined heat and power economic dispatch, International Journal of Electrical Power \& Energy Systems 43 (1) (2012) 1-5.

[28] M. Motevasel, A. R. Seifi, T. Niknam, Multi-objective energy management of chp (combined heat and power)-based micro-grid, Energy 51 (2013) 123-136.

[29] G. Piperagkas, A. Anastasiadis, N. Hatziargyriou, Stochastic pso-based heat and power dispatch under environmental constraints incorporating chp and wind power units, Electric Power Systems Research 81 (1) (2011) 209-218.

[30] D. Wei, A. Chen, B. Sun, C. Zhang, Multi-objective optimal operation and energy coupling analysis of combined cooling and heating system, Energy 98 (2016) 296-307.

[31] M. Bornapour, R.-A. Hooshmand, A. Khodabakhshian, M. Parastegari, Optimal stochastic coordinated scheduling of proton exchange membrane fuel cell-combined heat and power, wind and photovoltaic units in micro grids considering hydrogen storage, Applied Energy 202 (2017) 308-322.

[32] X. Chen, C. Kang, M. O'Malley, Q. Xia, J. Bai, C. Liu, R. Sun, W. Wang, $\mathrm{H}$. Li, Increasing the flexibility of combined heat and power for wind power integration in china: Modeling and implications, IEEE Transactions on Power Systems 30 (4) (2015) 1848-1857.

[33] A. Bischi, L. Taccari, E. Martelli, E. Amaldi, G. Manzolini, P. Silva, S. Campanari, E. Macchi, A detailed milp optimization model for combined cooling, heat and power system operation planning, Energy 74 (2014) 12-26.

[34] M. A. Lozano, J. C. Ramos, L. M. Serra, Cost optimization of the design of chcp (combined heat, cooling and power) systems under legal constraints, Energy 35 (2) (2010) 794-805.

[35] P. Arcuri, G. Florio, P. Fragiacomo, A mixed integer programming model for optimal design of trigeneration in a hospital complex, Energy 32 (8) (2007) 1430-1447.

[36] J. Sachs, O. Sawodny, Multi-objective three stage design optimization for island microgrids, Applied Energy 165 (2016) 789-800.

[37] L. Guo, W. Liu, J. Cai, B. Hong, C. Wang, A two-stage optimal planning and design method for combined cooling, heat and power microgrid system, Energy Conversion and Management 74 (2013) 433-445.

[38] B. Howard, V. Modi, Examination of the optimal operation of building 
scale combined heat and power systems under disparate climate and ghg emissions rates, Applied Energy 185 (2017) 280-293.

[39] gurobi, gurobi (2017).

URL http: //www . gurobi.com/resources/getting-started/mip-bas

[40] S. Parhoudeh, A. Baziar, A. Mazareie, A. Kavousi-Fard, A novel stochastic framework based on fuzzy cloud theory for modeling uncertainty in the micro-grids, International Journal of Electrical Power \& Energy Systems 80 (2016) 73-80.

[41] A. Zakariazadeh, S. Jadid, P. Siano, Smart microgrid energy and reserve scheduling with demand response using stochastic optimization, International Journal of Electrical Power \& Energy Systems 63 (2014) 523-533.

[42] Y. Xiang, J. Liu, Y. Liu, Robust energy management of microgrid with uncertain renewable generation and load, IEEE Transactions on Smart Grid 7 (2) (2016) 1034-1043.

[43] E. Kuznetsova, Y.-F. Li, C. Ruiz, E. Zio, An integrated framework of agent-based modelling and robust optimization for microgrid energy management, Applied Energy 129 (2014) 70-88

[44] A. Hussain, V.-H. Bui, H.-M. Kim, Robust optimization-based scheduling of multi-microgrids considering uncertainties, Energies 9 (4) (2016) 278.

[45] G. Liu, K. Tomsovic, Robust unit commitment considering uncertain demand response, Electric Power Systems Research 119 (2015) 126-137.

[46] F. Valencia, J. Collado, D. Sáez, L. G. Marín, Robust energy management system for a microgrid based on a fuzzy prediction interval model, IEEE Transactions on Smart Grid 7 (3) (2016) 1486-1494.

[47] M. Ebrahimi, A. Keshavarz, Climate impact on the prime mover size and design of a cchp system for the residential building, Energy and Buildings 54 (2012) 283-289.

[48] Y. Ruan, Q. Liu, Z. Li, J. Wu, Optimization and analysis of building combined cooling, heating and power (bchp) plants with chilled ice thermal storage system, Applied Energy 179 (2016) 738-754.

[49] A. Maleki, A. Askarzadeh, Comparative study of artificial intelligence techniques for sizing of a hydrogen-based stand-alone photovoltaic/wind hybrid system, international journal of hydrogen energy 39 (19) (2014) 9973-9984.

[50] A. Fetanat, E. Khorasaninejad, Size optimization for hybrid photovoltaicwind energy system using ant colony optimization for continuous domains based integer programming, Applied Soft Computing 31 (2015) 196-209.

[51] A. Maleki, A. Askarzadeh, Artificial bee swarm optimization for optimum sizing of a stand-alone $\mathrm{pv} / \mathrm{wt} / \mathrm{fc}$ hybrid system considering lpsp concept, Solar Energy 107 (2014) 227-235.

[52] Y. A. Katsigiannis, P. S. Georgilakis, E. S. Karapidakis, Hybrid simulated annealing-tabu search method for optimal sizing of autonomous power systems with renewables, IEEE Transactions on Sustainable Energy 3 (3) (2012) 330-338.

[53] A. Maleki, M. Ameri, F. Keynia, Scrutiny of multifarious particle swarm optimization for finding the optimal size of a pv/wind/battery hybrid system, Renewable Energy 80 (2015) 552-563.

[54] Z. Beihong, L. Weiding, An optimal sizing method for cogeneration plants, Energy and Buildings 38 (3) (2006) 189-195.

[55] O. Shaneb, G. Coates, P. Taylor, Sizing of residential $\mu \mathrm{chp}$ systems, Energy and Buildings 43 (8) (2011) 1991-2001.

[56] S. Sanaye, N. Khakpaay, Simultaneous use of mrm (maximum rectangle method) and optimization methods in determining nominal capacity of gas engines in cchp (combined cooling, heating and power) systems, Energy 72 (2014) 145-158.

[57] J. Wang, J. Sui, H. Jin, An improved operation strategy of combined cooling heating and power system following electrical load, Energy 85 (2015) 654-666.

[58] J. Wang, Y. Lu, Y. Yang, T. Mao, Thermodynamic performance analysis and optimization of a solar-assisted combined cooling, heating and power system, Energy 115 (2016) 49-59.

[59] J. Zhang, K.-J. Li, M. Wang, W.-J. Lee, H. Gao, A bi-level program for the planning of an islanded microgrid including caes, in: Industry Applications Society Annual Meeting, 2015 IEEE, IEEE, 2015, pp. 1-8.

[60] A. Khodaei, M. Shahidehpour, Microgrid-based co-optimization of generation and transmission planning in power systems, IEEE transactions on power systems 28 (2) (2013) 1582-1590.

[61] A. Khodaei, S. Bahramirad, M. Shahidehpour, Microgrid planning under uncertainty, IEEE Transactions on Power Systems 30 (5) (2015) 24172425 .
[62] Q. Zhu, X. Luo, B. Zhang, Y. Chen, Mathematical modelling and optimization of a large-scale combined cooling, heat, and power system that incorporates unit changeover and time-of-use electricity price, Energy Conversion and Management.

[63] S. G. Tesfahunegn, Fuel cell assisted photovoltaic power systems, Ph.D. thesis (2012).

[64] M. Lazaar, S. Bouadila, S. Kooli, A. Farhat, Comparative study of conventional and solar heating systems under tunnel tunisian greenhouses: Thermal performance and economic analysis, Solar Energy 120 (2015) 620-635.

[65] F. Laurencelle, R. Chahine, J. Hamelin, K. Agbossou, M. Fournier, T. Bose, A. Laperriere, Characterization of a ballard mk5-e proton exchange membrane fuel cell stack, Fuel Cells 1 (1) (2001) 66-71.

[66] B. Shabani, J. Andrews, S. Watkins, Energy and cost analysis of a solarhydrogen combined heat and power system for remote power supply using a computer simulation, Solar Energy 84 (1) (2010) 144-155.

[67] P. Pei, H. Chen, Main factors affecting the lifetime of proton exchange membrane fuel cells in vehicle applications: A review, Applied Energy 125 (2014) 60-75.

[68] P. Diéguez, A. Ursúa, P. Sanchis, C. Sopena, E. Guelbenzu, L. Gandía, Thermal performance of a commercial alkaline water electrolyzer: experimental study and mathematical modeling, international journal of hydrogen energy 33 (24) (2008) 7338-7354.

[69] $\varnothing$. Ulleberg, Modeling of advanced alkaline electrolyzers: a system simulation approach, International journal of hydrogen energy 28 (1) (2003) 21-33.

[70] F. Tietz, D. Sebold, A. Brisse, J. Schefold, Degradation phenomena in a solid oxide electrolysis cell after $9000 \mathrm{~h}$ of operation, Journal of Power Sources 223 (2013) 129-135.

[71] L. Bertuccioli, A. Chan, D. Hart, F. Lehner, B. Madden, E. Standen, Development of water electrolysis in the european union, Fuel Cells and Hydrogen Joint Undertaking (2014) 83.

[72] E. Krüger, Q. T. Tran, Minimal aging operating strategies for battery energy storage systems in photovoltaic applications, in: PES Innovative Smart Grid Technologies Conference Europe (ISGT-Europe), 2016 IEEE, IEEE, 2016, pp. 1-6.

[73] N. Omar, M. A. Monem, Y. Firouz, J. Salminen, J. Smekens, O. Hegazy, H. Gaulous, G. Mulder, P. Van den Bossche, T. Coosemans, et al., Lithium iron phosphate based battery-assessment of the aging parameters and development of cycle life model, Applied Energy 113 (2014) 1575-1585.

[74] S. Xinwei, H. Yingduo, Z. Shouzhen, J. Zheng, L. Qingsheng, N. Jing, Comprehensive power-supply planning for active distribution system considering cooling, heating and power load balance, Journal of Modern Power Systems and Clean Energy 3 (4) (2015) 485-493.

[75] F. Garcia, C. Bordons, Optimal economic dispatch for renewable energy microgrids with hybrid storage using model predictive control, in: Industrial Electronics Society, IECON 2013-39th Annual Conference of the IEEE, IEEE, 2013, pp. 7932-7937.

[76] H. Ren, W. Gao, Y. Ruan, Optimal sizing for residential chp system, Applied Thermal Engineering 28 (5) (2008) 514-523.

[77] G. Ferrari-Trecate, E. Gallestey, P. Letizia, M. Spedicato, M. Morari, M. Antoine, Modeling and control of co-generation power plants: a hybrid system approach, IEEE Transactions on Control Systems Technology 12 (5) (2004) 694-705.

[78] R. Atia, N. Yamada, Optimization of a pv-wind-diesel system using a hybrid genetic algorithm, in: Electrical Power and Energy Conference (EPEC), 2012 IEEE, IEEE, 2012, pp. 80-85.

[79] R. Dufo-López, J. L. Bernal-Agustín, J. Contreras, Optimization of control strategies for stand-alone renewable energy systems with hydrogen storage, Renewable energy 32 (7) (2007) 1102-1126.

[80] J. Löfberg, Automatic robust convex programming, Optimization methods and software 27 (1) (2012) 115-129. 